\title{
Philosophiques
}

\section{Millénarisme et situationnisme}

\section{Jean Roy}

Volume 8, numéro 1, avril 1981

URI : https://id.erudit.org/iderudit/203148ar

DOI : https://doi.org/10.7202/203148ar

Aller au sommaire du numéro

Éditeur(s)

Société de philosophie du Québec

ISSN

0316-2923 (imprimé)

1492-1391 (numérique)

Découvrir la revue

Citer cet article

Roy, J. (1981). Millénarisme et situationnisme. Philosophiques, 8(1), 3-48.

https://doi.org/10.7202/203148ar

Ce document est protégé par la loi sur le droit d'auteur. L'utilisation des services d'Érudit (y compris la reproduction) est assujettie à sa politique d'utilisation que vous pouvez consulter en ligne.

https://apropos.erudit.org/fr/usagers/politique-dutilisation/
Cet article est diffusé et préservé par Érudit.

Érudit est un consortium interuniversitaire sans but lucratif composé de l’Université de Montréal, l'Université Laval et l'Université du Québec à Montréal. Il a pour mission la promotion et la valorisation de la recherche. https://www.erudit.org/fr/ 


\title{
Millénarisme et situationnisme ${ }^{1}$
}

\author{
par Jean Roy
}

"Leur côté millénariste m’exaspérait. Je leur démontrais qu’il ne fallait pas confondre la révolution et l'avènement du royaume de Dieu sur la terre, que leurs rêves quarante-huitards s'opposaient radicalement à l'état des forces productives, qui imposait les grandes organisations économiques, politiques, administratives dont ils avaient la nausée. Ils (les contestataires de mai 68 ) souffraient de voir retourner contre eux le vocabulaire marxiste où ils cherchaient une légitimation. Mais ils n'étaient pas convaincus du tout.»

M. Duverger.

Par la rapidité et l'ampleur de son extension, Mai 68 a pris tout le monde par surprise. Aujourd'hui encore, il ne manque pas d'observateurs et d'analystes pour hésiter entre un diagnostic "léger» et un diagnostic «lourd» ${ }^{2}$. Plus de dix ans après, comment expliquer cette irruption soudaine et généralisée de l'irrationnel? Car, enfin, la disproportion entre les griefs formulés et l'exaltation extrême des comportements, la fascination éblouie et, en certains cas, la participation enthousiaste de nombre d'étu-

1. Les situationnistes ont exprimé leurs vues dans leur revue Internationale situationniste, réimprimée par procédé photomécanique en 1975 aux Éditions Champ-Libre. La revue comprend douze numéros qui paraissent irrégulièrement de juin 1958 à septembre 1969. Nous la citons sous le sigle IS; le premier chiffre renvoie au numéro, le second à la page.

La bibliographie situationniste comprend également quatre livres:

Guy Debord, La société du spectacle, Buclet-Chastel, 1967.

Raoul Vaneigem, Traité de savoir-vivre à l'usage des jeunes générations, Gallimard, 1967, 1974.

René Viénet, Enragés et situationnistes dans le mouvement des occupations, Gallimard, 1968.

$\mathrm{G}$. Debord et $\mathrm{G}$. Sanguinetti, La véritable scission dans l'Internationale, circulaire publique de l'Internationale situationniste. Éditions Champ-Libre, Paris, 1972. Dans ce dernier texte, vraisemblablement rédigé par «le général Debord", la dénonciation personnelle submerge l'élaboration théorique. Faute d'informations fiables sur la désintégration du groupe, nous nous proposons de revenir, le cas échéant, sur l'interprétation de ces «thèses» et fragments divers.

À moins d'indications contraires les soulignés sont des auteurs cités.

2. E. Morin, L'esprit du temps 2, Nécrose, B. Grasset, 1975, p. 43; Dans son dernier livre, La séduction de l'esprit, Seuil, 1972, H. Cox choisit la seconde interprétation: «Je crois personnellement que ces quelques semaines fascinantes ont été un point culminant de l'histoire politique et culturelle moderne» (p. 174). 
diants modérés et d'adultes apparemment bien intégrés à cette société de consommation, ces traits étaient manifestes.

La grille marxiste orthodoxe manque lourdement la cible. Étant en dehors du processus de production, l'étudiant n'est à proprement parler ni exploiteur ni exploité.

L'herméneutique freudienne, dans la mesure où elle se fonde sur la primauté du désir et de l'imaginaire, s'avère déjà plus féconde que la problématique de la satisfaction des besoins. En dépit de la référence appuyée aux lieux communs de la théorie marxiste, la réactivation flamboyante des thèmes surréalistes sautait aux yeux. Peu après, Marcuse devait déclarer: "C'est peut-être, pour moi, l'aspect le plus intéressant de Mai, la jonction de Marx et d'André Breton. L'imagination au pouvoir, ça, c'est vraiment révolutionnaire ${ }^{3}$.» La poussée libertaire fut telle que la "pratique théorique» du prolétariat apparut à plusieurs en total désaccord avec l'explosion surgie des profondeurs. Cette philosophie glacée n'était qu'une "philosophie de l'ordre», et «l'althussérisme est mort sur les barricades de Mai avec bien d'autres idées du passé ${ }^{4} »$. Bref, par sa base anthropologique comme par le topos sociologique de la nouvelle impulsion révolutionnaire et le foisonnement baroque de ses références théoriques, le mouvement de Mai échappe totalement au schéma du marxisme orthodoxe. La violence "révolutionnaire» ne provenait pas de la pression du besoin vital dans le prolétariat industriel, mais des aspirations transéconomiques aussi puissantes que vagues d'étudiants gauchistes vivant dans une société d'abondance.

Pourtant, par-delà la théorie "scientifique» du Capital, l'insurrection de la jeunesse en colère retrouvait les accents millénaristes du jeune Marx, mais aussi le pathos typique de tous "les fanatiques de l'Apocalypse». Dès le mois de juin, Sartre relativisait l'échec de «la révolution» de Mai en la rapportant au rêve millénariste. En procédant à l'autopsie de l'illusion, il reconnaissait sa puissance agissante: "D'une certaine façon ... le mouvement a échoué. Mais il n'a échoué que pour ceux qui ont cru que la révolution était à portée de la main, que les ouvriers allaient suivre les étudiants jusqu'au bout, que l'action déclenchée à

3. H. Marcusse, L'Express, 23-29 septembre 1968.

4. J. Rancière, La leçon d'Altbusser, NRF, 1974, p. 9-10. 
Nanterre et à la Sorbonne déboucherait sur une apocalypse sociale et économique qui provoquerait, non seulement la chute du régime mais la désintégration du système capitaliste. C'était un rêve ... ${ }^{5} \mathrm{Il}$ y revient dans un entretien avec trois rédacteurs de la New Left Review, reproduit dans le Nouvel Observateur du 26 janvier 1970: "L'idée d'une libération totale et instantanée est une utopie. Nous pouvons déjà prévoir certaines des limites et des contraintes qui s'imposeraient à une révolution future. Mais celui qui en tire argument pour ne pas faire la révolution, pour ne pas lutter dès maintenant pour elle, est tout simplement un contrerévolutionnaire.» On le voit, les exigences de la lucidité étant sauves, il veille cependant à ne pas décourager les révolutionnaires potentiels. La tentation implicite de la démobilisation est aussitôt barrée par l'argument terroriste.

Aux rencontres internationales de Genève (1969), Aron reprenait à son compte l'expression «anabaptistes de la société de bien-être» pour désigner les étudiants en révolte. Du même coup, il notait l'affinité historique du gauchisme et du clergé radical, notamment des «théologiens de la violence». Évoquant l'émancipation révolutionnaire de Münzer, Marx déclarait déjà: «À cette époque l'action la plus radicale de l'histoire allemande, la guerre des paysans, a échoué devant la théologie. Aujourd'hui que la théologie elle-même a échoué, la réalité la moins libre de l'histoire allemande, notre statu quo, se brisera contre la philosophie...» ${ }^{6}$. Cette brève reconnaissance généalogique ne devait pas rester sans suite. En 1850, Engels consacre une étude à $L a$ guerre des paysans en Allemagne. En 1921, E. Bloch reprit à fond toute la question dans son Thomas Münzer, théologien de la révolution. En 1957, N. Cohn publia son livre fameux: il n'a pas oublié T. Münzer.

Que de jeunes intellectuels, fils de bourgeois pour la plupart, puissent se réclamer ouvertement de la tradition millénariste a de quoi surprendre. Que leur influence déborde le cercle étroit de groupuscules de gauche, qu'ils lèvent le poing avec eux, qu'ils préparent et jouent un rôle actif en 68 ajoute à l'étonnement. Mais la teneur millénariste du mouvement fut trop importante pour qu'elle échappe à l'observation. Dans la présentation

S. J.P. Sartre, Interview donnée au Nouvel Observateur, 19 juin 1968.

6. K. Marx, Contribution à la critique de la philosophie du droit de Hegel, Aubier, 1971, p. 83. 
de son abondante récolte de textes et de documents de la crise, $\mathrm{P}$. Vidal-Naquet relevait quelques incohérences et concluait en lançant cette remarque programmatique: "Ces contradictions se résument peut-être en une autre plus fondamentale et qui tient, semble-t-il, dans le caractère «apocalyptique» et millénariste du mouvement révolutionnaire (...) Il y aurait toute une recherche à faire sur la présence du millénarisme dans le mouvement ${ }^{7}$.»

Dans cet article, nous nous proposons d'apporter une contribution à cette proposition en prenant comme champ d'investigation les situationnistes de Strasbourg et de Paris. En effet, par la radicalité de leur critique, par la qualité théorique et littéraire de leurs écrits, par leur pureté sectaire et leur rôle dans le mouvement des occupations, ils méritent une attention particulière.

«Les événements», comme on devait les appeler par la suite, ont porté à l'avant-scène $\mathrm{D}$. Cohn-Bendit, $\mathrm{A}$. Sauvageot et $\mathrm{A}$. Geismar. En réalité, ils furent les «leaders apparents d'un mouvement sans leaders» ${ }^{8}$. Ces chefs improvisés, rapidement devenus vedettes par l'action des mass média, ont repoussé au second plan l'action des situationnistes dont on a notablement sous-estimé l'impact ${ }^{9}$. Dany-le-Rouge a été l'instigateur et le plus volubile porte-parole du mouvement. Les deux autres, respectivement vice-président de l'Union nationale des étudiants de France (UNEF) et secrétaire général du Syndicat national des enseignants du Supérieur (SNESUP) tentèrent tant bien que mal de le diriger selon les poussées du moment. À la veille de la grande révolte, il convient de noter au passage la profonde décomposition de l'UNEF. Les déchirements internes étaient tels que «depuis 1965 aucun bureau national n'a pu se maintenir pendant l'année réglementaire ${ }^{10}$ ». Elle formait un milieu abstrait, sans prise sur les aspirations des étudiants: «c'était vraiment un monde clos qui ne représentait rien: tout ne servait qu’à créer un rapport de force pour prendre la présidence ${ }^{11}$.» La masse étudiante flottait à la dérive, sans organisation réelle. Nanterre n'y avait pas de représentants. Malgré tout, Cohn-Bendit parvint à prendre la parole pour

7. A Schnapp et P. Vidal-Naquet, Journal de la commune étudiante, Textes et documents, Seuil, 1969 , p. 50,66

8. R. Viénet, Enragés et Situationnistes dans le mouvement des occupations, NRF, 1968, p. 54.

9. A. Willener, L'image-action de la société ou la politisation culturelle, Seuil, 1970, p. 144.

10. A. Schnapp et P. Vidal-Naquet, op. cit., p. 15.

11. D. Cohn-Bendit, Le grand bazar, Belfond, 1975, p. 26. 
dire la profonde insatisfaction des étudiants et prophétiser l'occupation prochaine des bâtiments universitaires. Cette déclaration fut accueillie avec un grand éclat de rire... Ex-militant du P.S.U. depuis trois ans, Geismar avait lui aussi senti arriver "le mouvement» ${ }^{12}$. Mais le plus déraciné des trois fut sans conteste Cohn-Bendit, juif né en Allemagne, bâtard, orphelin, éduqué tantôt en Allemagne tantôt en France. Avant et après Mai, on le voit errer en quête d'une identité, d'un enracinement, d'une communauté. Conscient de l'importance de ce problème il observe, dès la première page de son livre récent, Le grand bazar: «Les dimensions multiples de ma personnalité témoignent aussi de l'expression de l'incohérence de la société moderne ${ }^{13}$... Le mouvement du 22 mars lui fournit un moment un pôle de rattachement fort composite et mobile: «Ma vie sociale, et même mon existence matérielle, dépend de la force du mouvement. Tout ce que je peux être, je le suis par lui, et sans lui je ne suis plus rien. Ainsi confondu existentiellement au mouvement, je me prends souvent comme sa juste image. Le mouvement devient quasiment mon nouveau sur-moi ${ }^{14}$.» Cependant, au sein même du mouvement, Cohn-Bendit apparaît au situationniste René Viếnet en marge de ce groupe marginal; se situant dans la tendance la plus radicale du « 22 mars", il «se trouvait même être plus réellement révolutionnaire que tout le reste du mouvement dont il devint le porte-parole, et qu'il dut donc supporter ${ }^{15}$ ». Du trio dirigeant du grand mouvement de Mai, c'est «celui qui sut en refléter un peu mieux le contenu radical ${ }^{16}$ ». Les rapports avec «les copains" se détériorièrent rapidement. De retour en France après son expulsion en Allemagne, il avoue: «Je n'étais plus capable d'assumer le rôle que j'avais, parce que je n'avais plus la possibilité de me réintégrer dans le groupe, ce qui aurait été la seule solution. Alors, je suis parti. C'était vraiment la fuite. (...) J'étais complètement déboussolé . . . Arrivé en Allemagne, j'étais vide, je n'avais pas de racines. (. . .) Je me sentais émigré, je faisais n'importe quoi ${ }^{17}$.» Finalement la solution a été «l'établissement», c'est-à-dire «l'acte par lequel des militants d'origine étudiante

12. P. Labro, «Ce n'est qu'un début», Denoël, 1968, p. 178-9.

13. D. Cohn-Bendit, op. cit., p. 9.

14. Ibid, P. 21.

15. R. Viénet, op. cit., p. 38.

16. lbid., p. 54 .

17. D. Cohn-Bendit, op. cit., p. 57-58. 
s'installent dans le prolétariat en y travaillant ${ }^{18}$ ». À défaut de pouvoir s'intégrer dans la société existante et d'en créer une autre selon ses voeux, il rejoint les autres "déracinés» (les travailleurs immigrés) pour composer une microcommunauté de vie, de travail et de lutte «révolutionnaire» en attendant des jours meilleurs où l'espérance pourra se ré-actualiser sous des formes nouvelles. Car l'exaltation du combat révolutionnaire et l'espoir d'une société festive ont été trop intensément investis pour être abandonnés: «La société des barricades c'est l'irruption de l'avenir dans le présent. ( . . .) Tout est possible. La politique-fiction est à l'ordre du jour. La transformation radicale et libératrice des sociétés occidentales n'est pas le rêve d'une poignée de militants. Elle peut correspondre à une attente largement partagée ${ }^{20}$.»

Ainsi, quels que soient les revers immédiats, l'avenir demeure ouvert et donne sens au présent. Celui qui est habité par un tel état d'esprit est disponible pour n'importe quelle aventure. Son volontarisme schizophrénique surcompense son impuissance et son vertige.

Ainsi le drame personnel du déracinement lié à un sentiment plus large de l'aliénation propre à une société anomique et mouvante peut entraîner à la réactivation du vieux millénarisme sous le travesti moderne du révolutionnarisme. Mais pour être plus «spectaculaire» la figure de Cohn-Bendit dissimulait autant qu'elle l'exprimait une théorie millénariste autrement radicale et consciente d'elle-même. S'il est vrai que la participation de l'Internationale situationniste au « 22 mars» fut nulle selon $\mathrm{R}$. Viénet ${ }^{21}$, en revanche, Cohn-Bendit connaissait bien les thèses situationnistes et, à l'occasion, les utilisa; présidant la «Commission Culture et Créativité», celle-ci afficha sur les murs de la Sorbonne des citations de l'I.S., notamment du livre de Vaneigem $^{22}$.

Avant de dégager la composante millénariste de ce groupe, rappelons schématiquement le scénario général de ce type de mouvement social.

18. Ibid., p. 117.

19. D. Cohn-Bendit, op. cit., p. 12,58 .

20. Ibid., p. 40, 107.

21. R. Viénet, op. cit., p. 38, n. 1 .

22. Ibid., p. 77. 
Dans un état de crise, un groupe prend confusément conscience de lui-même comme catégorie traquée par l'histoire. Démuni, impuissant, humilié, il compense son infériorité réelle par la projection imaginaire d'une société autre, d'une alternative radicalement nouvelle, dans laquelle le mal serait définitivement surmonté, l'humanité régénérée. Du fond de sa misère, il se prend à espérer un renversement brusque et total de sa situation. Ia conscience de l'anéantissement rebondit en anticipation délirante d'un accomplissement total imminent. Le groupe-paria se redresse, se met en route vers la réalisation de son rêve fousublime. La perspective enfiévrée d'une fin prochaine de la misère court-circuite le calcul rationnel des forces disponibles et l'application patiente des médiations concrètes. La violence vient habituellement combler le fossé entre la réflexion stratégique et l'impatience eschatologique. L'agressivité latente du groupe est éperonnée par la conviction manichéenne d'incarner l'absolu prochain du Bien contre les forces liguées du Mal. La résistance qui ne peut manquer de se former suscite souvent un véritable délire paranoïaque. La hantise du complot et la bonne conscience messianique s'aiguillonnent et se renforcent mutuellement. L'opposition tranchée du Mal et du Bien, du Rien et du Tout et le passage imminent de l'un à l'autre caractérisent l'aspiration millénariste d'un salut terrestre.

On le comprend sans peine, le mythe d'un renversement complet de l'ordre du monde peut induire chez le groupe qui s'en nourrit un dynamisme, une énergie indomptables. Et il arrive qu'à partir du possible ardemment espéré, le réel cède et des peuples se libèrent effectivement de l'oppression. À l'éthos hérö̈que du combat succède alors l'éthos «bourgeois» d'une nouvelle société en voie de stabilisation. L'esprit révolutionnaire s'objective dans des institutions et des rites qui structurent un nouvel ordre qui, à la longue, se sclérose et suscite à son tour un vent de révolte. Le mythe du salut ici et maintenant si on le veut vraiment, la croyance à la génération de l'homme total à travers le creuset d'une révolution totale accomplie par la classe totalement aliénée, voilà ce que nous trouvons au coeur du «situationnisme». Certes, le noyau mythique est savamment enveloppé dans un langage conceptuel, mais né dans une intelligentsia à laquelle il est destiné, il ne faut pas s'étonner si le message millénariste parle 
la langue de son temps. Logique du mouvement, de la contradiction et de la totalité, la dialectique hégélo-marxiste se prête merveilleusement à cette intellectualisation. Le mythe du monde renversé reçoit de cette palette conceptuelle une allure rationnelle, une sorte de respectabilité philosophique qui lui garantit son pouvoir de séduction et sa force d'entrainement chez les modernes que nous sommes. Mais ce qui émeut et pousse à l'action, c'est le mythe, ainsi que l'a bien vu Sorel, et non pas les pesantes élucubrations de la raison théoricienne. Le langage dialectique assure la réception sociale du contenu idéo-moteur du mythe, il n'altère pas son essence.

Dans La société du spectacle, G. Debord décèle dans le messianisme judéo-chrétien et les communautés chrétiennes primitives le ferment millénariste qui éclate dans la révolte des paysans allemands. Car la compromission du christianisme avec le pouvoir impérial et la consécration idéologique de l'Église comme royaume déjà réalisé ( $\mathrm{S}$. Augustin) n'ont pas anéanti le message d'espérance que reconnaissent aussitôt les déshérités et qu'ils retournent contre l'institution théoriquement destinée à le transmettre. C'est dans l'ici-bas de notre histoire que le Royaume devait advenir. Mais, estime-t-il, "ce ne sont pas, comme croit le montrer Norman Cohn dans Les fanatiques de l'Apocalypse, les espérances révolutionnaires modernes qui sont des suites irrationnelles de la passion religieuse du millénarisme. Tout au contraire, c'est le millénarisme, lutte de classes révolutionnaire parlant pour la dernière fois la langue de la religion, qui est déjà une tendance révolutionnaire moderne, à laquelle manque encore la conscience de n'être qu'bistorique. Les millénaristes devaient perdre parce qu'ils ne pouvaient reconnaître la révolution comme leur propre opération» ${ }^{23}$. Aussi, à ses yeux, la langue archaïque de l'hérésie chrétienne n'est qu'une expression déguisée de la praxis révolutionnaire moderne désormais dépouillée de ses oripeaux théologiques, rendue à la vérité de son essence séculière, intégralement historique. Dans cette optique, la Révolution est l'essentiel, le langage religieux l'inessentiel: la praxis radicale n'entretient qu'un lien circonstancié, contingent, avec l'aspiration à la Transcendance.

En réalité, nous sommes ici au point d'interpénétration de la religion et de la politique. D'un côté, il est vrai de dire, avec $\mathrm{V}$. 23. G. Debord, La société du spectacle, Buchet-Chastel, 1967, p. 116. Souligné dans le texte. 
Matthieu, que «l'espérance dans la révolution n'est pas le simple succédané de l'espérance dans la vie éternelle, c'est la même espérance, sécularisée ${ }^{24}$ ». C'est ainsi que Spranger, Aron, Monnerot ont pu parler de «religion séculière» pour désigner les totalitarismes de notre temps: «seule la religion résout tout sur tous les plans $^{25} »$. Mais, dans cette confusion où millénarisme et révolutionnarisme moderne mélangent leurs eaux, les proportions peuvent varier: «Les premiers révolutionnaires sont, en vérité, les Puritains. (...) Les anabaptistes du siècle précédent qui voulaient construire la «nouvelle Jérusalem» ici-bas, sur cette terre, continuaient pourtant d'avoir des aspirations religieuses. Pour les Puritains, au contraire, l'étendard religieux n'est pas ce qui compte le plus. D’une religiosité anthropocentrique ils passent à une vision essentiellement politique de la rénovation. Le rapport entre religion et politique est inversé: c'est la religion, et non plus la politique, qui est «superstructure». (. . .) Si pour les Juifs, le prophétisme est accidentellement politique et essentiellement religieux, chez Cromwell le rapport est inversé. Devenu politique, le prophétisme devient dictature ${ }^{26}$."

D'autre part, la politique révolutionnaire qui se veut purement historique n'en garde pas moins un aspect religieux dans la mesure où elle véhicule une aspiration à l'Absolu, à la Totalité, Mais en s'objectivant dans l'ici-bas de la lutte politique, cette noble passion devenue folle bouche l'ouverture à un au-delà de la mort sans lequel le concept de religion ne trouve plus d'assise ferme. La politique cesse d'être affrontement d'intérêts et d'opinions proprement politiques pour devenir Terreur. Il ne reste plus de place pour un justus hostis. L'ennemi satanisé, le combat devient inexpiable. Chaque enjeu ou plutôt l'enjeu étant illimité, les moyens de lutte le deviennent également. En sacralisant le Pouvoir (à conquérir ou effectivement exercé), la religion se confond avec un ordre social particulier. C'est pourquoi Aron peut, sans contradiction, revenir sur son expression pour en marquer la limite essentielle: «J'ai été opposé à ce que j'ai baptisé les religions séculières, parce que la religion séculière - j'ai employé cette expression pendant la guerre pour désigner à la fois

24. V. Matthieu, Phénoménologie de l'esprit révolutionnaire, Calmann-Lévy, 1974, p. 252.

25. J. Monnerot, Sociologie du communisme, NRF, 1949, p. 283.

26. V. Matthieu, op. cit., p. 253-4. 
le fascisme et le communisme - me paraît une profanation de l'esprit religieux, en ce sens que toute religion politique consiste à transfigurer en valeur absolue une certaine organisation de la société. Or l'essence de la religion, pour moi, bien que ce ne soit une définition ni sociologique, ni historique, est de dévaloriser la société en tant que telle, la hiérarchie sociale en tant que telle ${ }^{27}$.» L'histoire de l'Occident ${ }^{28}$ a abondamment démontré à quel point le millénarisme chrétien et le césaropapisme constantinien ${ }^{29}$, tout comme le mythe intellectualisé de la Révolution et les totalitarismes, ont perverti aussi bien la politique que la religion; ni l'État laïc autonome ni le sens d'un au-delà du monde n'y ont trouvé leur compte. Mais, il est également possible d'observer dans les pays du tiers-monde les excentricités tantôt comiques tantôt terribles qu'entraîne l'impossible fusion de ces deux activités essentiellement humaines ${ }^{30}$.

En dépit de sa richesse théologique, le projet moltmannien d'un nouveau christianisme qui «dépasserait» dans une synthèse originale messianisme historique et religion transcendante aboutit en fait à un amalgame douteux ${ }^{31}$. En tout cas, la synthèse hégélienne est autrement différenciée ${ }^{32}$.

27. R. Aron, Quelle crise? Quelle société?, Presses universitaires de Grenoble, 1974, p. 48.

28. La plupart de ces mouvements sont d'inspiration chrétienne, nationaliste, socialiste ou anarchiste, mais il arrive que, même dans l'Europe moderne, des groupes puisent dans leur propre fonds les motifs de leur révolte, relativement en marge des doctrines constituées. Voir E.J. Hobsbawm, Les primitifs de la révolte dans l'Europe moderne, Fayard, 1966.

29. L'incident de Canossa montre bien malgré tout qu'au sommet de sa puissance, l'Église ne prétendait pas remplir l'office de la politique. Après son geste de soumission, Henri IV fut réintégré dans ses droits royaux.

30. Voir, en particulier, W.E. Mühlmann, Messianismes révolutionnaires du tiers-monde, NRF, 1968.

31. C'est ainsi qu'il écrit dans L'espérance en action, Seuil, 1973, p. 11-12: "L'Ancien testament n'est pas un livre très religieux; c'est le livre d'un messianisme historique et il est par conséquent très politique. Un christianisme qui ne pense plus sur ce terrain-là, qui ne croit ni n'espère plus sur ce terrain-là, se mue en religion de l'au-delà et cesse de signifier une espérance vivante pour le monde. En se séparant de l'Église, l'espérance d'Isrä̈l - quoique tournée vers le monde - devint provincialiste: l'espérance de l'Église, au contraire, devint universelle, mais se détourna du monde.

Seule la fusion entre l'espérance d'Israël et de ses prophètes et l'espérance des chrétiens et de leurs apôtres peut produire - comme le dit Harvey Cox - une espérance qui soit tournée vers le monde, terrestre et politique, et en même temps universelle et totale. Seule une espérance qui réunisse Royaume et Résurrection peut éclairer de sa lumière l'Exil et la Croix. C'est parce que l'Église demeure encore prise dans cette première séparation (dont elle cherche aujourd'hui seulement à triompher peu à peu), qu'elle a tant de peine à se débarrasser de la religion et à reconnaître les mouvements révolutionnaires modernes comme des frères du même sang."

32. E. Weil, «La sécularisation de l'action et de la pensée politiques à l'époque moderne», Essais et conférences, t. II, Plon, 1971. 
Quoi qu'il en soit, si Debord ne craint pas de s'approprier les millénarismes du Moyen Âge par le biais de la «traduction» dans le langage moderne de la dialectique, Vaneigem ne prétend pas non plus se démarquer plus qu'il ne faut à leur égard: Ils ne disent pas plus que lui, mais autrement:

Il n'y a plus aujourd'hui d'hérétiques. Le langage théologique dans lequel s'exprimèrent tant d'admirables soulèvements fut la marque d'une époque, le seul langage possible, sans plus. Il faut désormais traduire. Et la traduction va de soi. Compte tenu de mon temps, et de l'aide objective qu'il m'apporte, qu'ai-je dit de plus au $\mathrm{XX}^{\mathrm{e}}$ siècle que ces Frères du Libre Esprit déclarant au XIII ${ }^{\mathrm{e}}$ : «On peut être à ce point uni à Dieu que, quoi qu'on fasse, on ne puisse pécher. J'appartiens à la liberté de la Nature et je satisfais tous les désirs de ma nature. L'homme libre a parfaitement raison de faire tout ce qui lui procure du plaisir. Que le monde entier soit détruit et périsse totalement plutôt qu'un homme libre s'abstienne de faire une seule action que sa nature le pousse à accomplir»? Et comment ne pas saluer Johann Hartmann: «L'homme véritablement libre est roi et seigneur de toutes les créatures. Toutes choses lui appartiennent, et il a le droit de se servir de toutes celles qui lui plaisent. Si quelqu'un l'en empêche, l'homme libre a le droit de le tuer et de prendre ses biens»? Ou encore ce Jean de Brünn qui décidant: «Toutes les choses que Dieu a créées sont communes à tous. Ce que l'oeil voit et convoite, que la main s'en saisisse», se justifiait ainsi d'avoir pratiqué la ruse, le brigandage et le vol à main armée? Ou les Pifles d'Arnold, purs à ce point que quoi qu'ils fissent, ils ne pouvaient pécher (1157)? Ces diamants du christianisme ont toujours brillé d'un éclat trop vif aux yeux chassieux des chrétiens. Quand l'anarchiste Pauwels dépose, le 15 mars 1894, une bombe à l'église de la Madeleine, quand le jeune Robert Burger égorge un prêtre le 11 août 1963, c'est la grande tradition hérétique qui se perpétue pauvrement mais dignement dans leur geste. Le curé Meslier et le curé Jacques Roux, fomentant jacqueries et émeutes, ont montré, à mon sens, la dernière reconversion possible du prêtre sincèrement attaché aux fondements révolutionnaires de la religion. Mais c'est ce que n'ont pas compris les sectateurs de cet oecuménisme contemporain qui va de Rome à Moscou et de la canaille cybernéticienne aux créatures de l'Opus Dei. À l'image de ce nouveau clergé, on devine sans peine ce que sera le dépassement des hérésies ${ }^{33}$.

Le recours insistant aux catégories hégéliennes ne laisse pas d'étonner le lecteur. Car enfin, il saute aux yeux qu'ils inversent complètement l'orientation foncièrement anti-utopique de l'hégé-

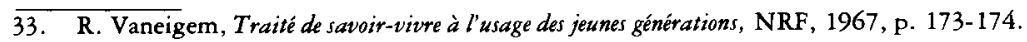


lianisme. La reconnaissance de la rationalité immanente du devenir historique, le rôle finalement subordonné de la fécondité de la négativité, le procès de la liberté abstraite et de la terreur révolutionnaire, surtout le rôle éminent de la totalisation politique dans l'action concrète frappent de plein fouet leurs thèses anarchosocialistes. Il est vrai qu'au-delà de l'esprit objectif, l'esprit absolu s'épanouit dans l'art, la religion et la philosophie. Inutile de préciser que, conformément à la tendance dominante de la tradition révolutionnaire européenne, les situationnistes ont peu d'inclination pour la fantasmagorie mystique ${ }^{34}$. Vaneigem réserve au christianisme des injures que n'aurait pas désavoués Nietzsche: "Partout, où la volonté de vivre n'émane pas spontanément de la poésie individuelle, s'étend l'ombre du crapaud crucifié de Nazareth ${ }^{35}$.» Quant à la philosophie moderne, ils en retiennent surtout la pente nihiliste. La critique situationniste est sans doute la démystification la plus impitoyable qu'il nous soit donné de lire aujourd'hui. On peut se demander par moments si la démolition systématique ne tourne pas effectivement à un nihilisme complet. Cette critique rageuse nous entraîne loin de la maxime d'inspiration hégélienne: «La première tâche de qui veut changer le monde est de le comprendre dans ce qu'il a de sensé ${ }^{36}$.» En revanche, la poésie et les valeurs esthétiques en général prennent à leurs yeux une densité révolutionnaire. C'est au nom de la Poésie, de l'Amour et de la Vie qui culminent dans la Fête qu'est menée la Révolution de la vie quotidienne. Ici ils sont certes plus près de Hegel que de Marx, plutôt fermé comme on sait à la profondeur spirituelle de l'art: "Marx renonce à analyser le Romantisme et le phénomène artistique en général: Lénine ignore presque systématiquement l'importance de la vie quotidienne, les futuristes, Maïakovsky et les dadaïstes ${ }^{37}$.»

34. Bien que les divergences ne manquent pas parmi les «radicaux», les hippies, la New Left, etc., il semble cependant que les «révohutionnaires» américains manifestent plus d'intérêt pour les poètes, visionnaires et grands spirituels que les gauchistes européens. La faveur des Ginsberg, Watts, Leary, Kesey indiquent une sensibilité particulière dont on ne trouve guère d'équiy̧alent en Europe: Sur un plan plus réflexif, Theodore Roszak oppose à la science et au réalisme technocratique la valeur permanente de l'art et de la religion qui dans la conjoncture présente prennent une charge critique singulière: «Le prophète de notre horizon historique c'est Blake, ce n'est pas Marx." (Oü finit le désert, Stock, 1973, p. 23.)

35. R. Vaneigem, op. cit., p. 117.

36. E. Weil, Philosopbie politique, Vrin, 1956, p. 57.

L'histoire anecdotique rapportée par Willener (op. cit., p. $218, n .1$ ) «que Lénine habitait non loin du café zurichois où se réunissait Tzara et les premiers dadaistes et qu'ils s'ignorèrent cordialement les uns les autres» est à cet égard tout à fait symbolique.

37. R. Vaneigem, op. cit, p. 182. 
Le drame fut que la part la plus vivante de la culture et les forces sociales les plus progressistes, le surréalisme et le matérialisme historique, l'art et la révolution dévièrent de leur trajectoire révolutionnaire et ne purent réaliser leur jonction salutaire. En voulant être scientifiques et réalistes, les marxistes ont tourné le dos à la négativité critique de la Poésie, et les surréalistes n’ont pas su recueillir la dynamite dadaïste dans sa totalité et incarner son contenu révolutionnaire dans l'Histoire. Les partis qui continuaient à se réclamer de la Révolution la trahissaient par la dictature ou le réformisme parlementaire et syndical, cependant que le surréalisme reniait l'insurrection du désir et du rêve dans un suivisme politique myope ou un esthétisme abstrait bientôt récupéré par la société spectaculaire (publicité, pop'art, etc.).

Avec un instinct très sûr, les situationnistes ont éprouvé l'affinité certaine de l'essentielle créativité de l'acte poétique et de la politique révolutionnaire. Chateaubriand l'avait aussi fortement senti: les poètes et les grands politiques, les Mirabeau, Danton, Robespierre, Bonaparte sont de la même race. De leurs mains impérieuses, ceux-ci pétrissent la matière sociale comme le poète manie souverainement la langue de la tribu. De son côté, Bloch prétend que le philistinisme bourgeois ne pouvait que développer une méfiance pleine d'hostilité à l'égard des maîtres de l'illusion et du rêve, car c'est dans la transfiguration de l'art que s'esquisse un premier renversement du monde des faits sur lesquels s'étend l'ombre de son pouvoir.

À cette opposition normale d'activités intrinsèquement distinctes s'ajoutent les conditions particulières de la société moderne. Ce sont les romantiques qui ont incarné avec le plus de vivacité la conscience malheureuse du nouvel état de choses. Placée sous le signe de la science et de la technique, vouée aux activités productives et utiles, la société industrielle n'a cessé de marginaliser ses artistes. Les "poètes maudits» sont les fils nécessaires de cet âge de fer. La masse des travailleurs produit dans des mégalopoles laides et sans joie des objets laids offerts à l'appétit du consommateur. Combien la situation de l'artiste de la Renaissance différait de la nôtre à cet égard! L'art est devenu une activité spécialisée pour un public de connaisseurs, littéralement une activité excentrique par rapport à l'activité besogneuse de la société. La division moderne du travail est pour le grand nombre 
la tristesse même. Dans ces conditions, on comprend que, face à une extériorité hostile, l'artiste se soit replié sur lui-même, souvent en proie à l'imprécation ou à la folie. Dans ce monde insensé mais rationalisé, surorganisé, «désenchanté», comment pourrait-il s'intéresser à une politique autre qu'anarchiste, plutôt révolutionnariste d'ailleurs que révolutionnaire?

Il est difficile pour la poésie de se réconcilier avec la prose de la vie quotidienne, avec l'ennui du labeur utilitaire médiatisé par la machine et le calcul de l'information. En revanche, la politique constitue une «nourriture psychique», voire une «société de consommation psychique» beaucoup plus satisfaisante pour l'individu. Bien que la politique efficace comporte elle aussi ses lois implacables, elle se prête davantage à l'aventure que la plate économie. L'épopée napoléonienne a soulevé une multitude enthousiaste et marqué pour le reste de leur vie des civils nostalgiques; de même, le grand happening révolutionnaire de Mai 68 a dispersé aux quatre vents une impérissable génération d'anciens combattants ... C'est par ce biais que romantisme et politique peuvent communiquer.

Par sa structure même, la société moderne ignore l'individu: il ne lui importe guère que l'un ou l'autre exerce telle ou telle fonction pourvu qu'elle soit bien remplie. Dans la compétition, les plus compétents doivent normalement s'imposer. Les individus sont interchangeables dès lors que les différents rouages du mécanisme social fonctionnent. Pour la plupart le travail demeure à la surface de leur personnalité, il n'engage pas leur moi profond. D'où l'inévitable sentiment d'ennui. Seul le temps de loisir constitue le moment où l'activité expressive du sujet peut se donner libre cours. En fait, cette portion est elle-même fort réduite par l'industrie et le commerce du loisir. Aliéné dans son travail, l'individu tend également à l'être dans son loisir. Au contraire, par son existence même, l'artiste est la vivante antithèse de ce type de société: la bohème devient tout naturellement un foyer de contestation. On comprend qu'en prenant conscience de sa place dans la société, l'intelligentsia littéraire soit si réceptive à l'égard des mouvements politiques radicaux, et spécialement à l'égard de la ligne révolutionnaire et anarchisante du marxisme. L'avant-garde esthétique tend à rejoindre l'avantgarde politique - ou du moins celle qui est considérée comme 
telle dans l'éventail politique. Cependant, contre les socialismes historiquement "arrivés», tous autoritaires et culturellement aussi répressifs que les bourgeois puritains, W. Reich et $\mathrm{H}$. Marcuse ont injecté dans le marxisme la dimension esthéticoérotique héritée des romantiques. C'est une question de savoir si l'injection vitaliste n'a pas exténué le marxisme de départ... L'extension de cette mixture idéologique à un milieu étudiant considérablement élargi, grâce à la croissance économique de l'après-guerre en Amérique puis en Europe, a entraîné un changement d'échelle qui a fourni l'assiette sociologique du gauchisme.

L'évolution de l'Internationale situationniste suit une évolution parallèle mais en sens inverse. En effet, le champ idéologique originel des situationnistes n'était pas marxiste mais lettriste ${ }^{38}$. Guy Debord, le $\mathrm{n}^{\circ} 1 \mathrm{du}$ situationnisme, son fondateur et son «meneur de jeu» ${ }^{39}$ (le terme «directeur» est ainsi soigneusement écarté) jusqu'à son éclatement final, participe à l'aventure lettriste vers 1950-52. En 1952, il constitua l'Internationale lettriste qui devait durer jusqu'en 1957. Le premier numéro de l'Internationale situationniste parut en juin 1958, le douzième et dernier numéro, en septembre 1969 . Or, il n'est pas sans intérêt de noter que, dans le sillage du surréalisme, le mouvement d'Isidore Golstein, alias Jean Isidore Isou, mêla un formalisme et une «mégalomanie égocentrique historique» de caractère fortement messianique. R. Estivals reconstitue succinctement sa démarche de la manière suivante:

«Je pouvais devenir oui, moi seul, le plus grand homme de mon temps», déclare Isou. Mais pour devenir grand homme, il faut faire ses preuves: «Il me fallait l'immortalité, il fallait que j'entre en chaque discipline et que je parvienne à être le seul maître...»

Pour cela il faut tout bouleverser, il faut être dieu. Isou sera donc le messie et pour y parvenir il se sert de l'histoire des religions où il

38. La section française fut aussi marquée par le Comité psychogéographique de Londres et l'Internationale des Artistes expérimentaux, dit mouvement COBRA (1949), lui-même issu du Mouvement pour un Bauhaus Imaginiste (1933) et du mouvement néerlandais «De Stijl», comme le révèle les premiers numéros de l'I.S. Mais la lignée dadaïsmesurréalisme-lettrisme, mieux enracinée en France, joua une influence prédominante à l'origine du situationnisme français. Voir là-dessus le livre d'Eliane Brau, Le situationnisme ou la nouvelle internationale, Nouvelles Éditions Debresse, 1968.

39. Foncièrement anarchiste, le groupe répugne, on le comprend, à la reproduction du commandement en son sein. Cetre expression, inspirée de Fourier (I.S., 11/38) n'annule pas cependant, dans la réalité, la discipline rigoureuse propre à toute secte même antiautoritaire dans son principe. 
introduit une première fois sa méthode dialectique subjectiviste. II découvre deux parties: le judaïsme ou thèse, le christianisme ou antithèse. L'isoüsme sera la synthèse. Ainsi: «Le juif est la normalité première ... P Par contre, le «christianisme est le judaïsme à rebours, inverti...» Enfin la troisième phase, la judaisation du monde et de la France, expressément proposée, se fera, sur le plan culturel, par Isou, le messie: «Le messie s'appelle Isidore Isou». (Ibid., p. 280) ${ }^{40}$.

Comme dans la théologie de la libération de Moltmann, la dialectique hégélienne apporte une formalisation philosophique à un néo-christianisme de type millénariste, de la même manière, l'isouïsme «répète» la dialectique ternaire de Hegel mais dans un sens radicalement opposé à son inspiration propre, dans un sens apparenté au gauchissement de Stirner plutôt que de Marx. Si dans le rapport individu-création tel que le conçoit Isou, l'oeuvre est dépréciée au profit de l'avènement du Moi -- l'oeuvre peut être littéraire ou politique, peu importe - , dans «la bande à Ben», l'oeuvre est franchement évacuée, et la preuve de Ben-dieu suprême ne peut être administrée que par l'activisme de la terreur...

Le jeune Debord a respiré cette atmosphère saturée de messianisme, mais, on ne le voit que trop, cette doctrine laisse peu de place aux adhérents éventuels, inévitablement voués à l'adoration. L'Internationale lettriste représentait sans doute une première échappée hors du goulot d'étranglement des solipsismes antagonistes. Il reste que, dans l'I.S. de 1958, Debord devait s'imposer par des procédés analogues. Il expulse presque aussitôt son compagnon Wolman . . . La double pratique de la rupture et de l'exclusion se transmit d'un mouvement à l'autre, et Debord réussit à se maintenir jusqu'en 1969 en qualité d'interprète final de l'orthodoxie et de l'orthopraxie. De ce fait, il assuma une autorité particulière, réprimant les moindres déviations par l'exclusion définitive. La structure conseilliste de l'I.S. n'a pas empêché l'un ou l'autre, le "directeur" G.E. Debord en l'occurrence, d'exercer une influence prépondérante. Il est piquant d'observer que "l'état-major» ${ }^{41}$ de l'anti-politique, comme tant d'autres, a dé-

40. R. Estivals, "De l'avant-garde esthétique à la révolution de mai”, Communications, 12 (1968), p. 87.

41. I.S., 8/27: «'L'I.S. ne peut être qu'une Conspiration des Égaux, un état-major qui ne veut pas de troupes." 
péri plutôt par suite de la négation idéaliste de la dimension politique de leur mouvement — «un seul héros: l' I.S.» — que par suite de l'éternelle politique de leurs attaques.

Le subjectivisme radical qui sévissait dans le lettrisme ne fut pas totalement rejeté - la libération totale ne peut être qu'individuelle et collective inséparablement - , mais s'est trouvé considérablement «réduit» par l'intégration d'une nouvelle perspective idéologique: le marxisme. De ce point de vue, les audaces les plus téméraires de l'aventure esthétique moderne n'échappent pas à l'assimilation d'un système socio-politique essentiellement aliénant. L'oeuvre d'art-marchandise tombe sous la coupe récupératrice du marché. L'activité esthétique, en tant qu'activité spécialisée s'exprimant dans des oeuvres particulières destinées à la jouissance passive d'un public cultivé, laisse intactes les structures de la société. Bien plus, les cris les plus stridents de la révolte dadaiste puis surréaliste, ceux de Sade, Fourier, Lautréamont, finissent par faire partie du patrimoine de la culture transmise aux jeunes générations. De ces héros de la subversion culturelle, le surréalisme «en écrit tant et si bien qu'il obtient pour ses protégés une mention honorable dans le panthéon des programmes scolaires $^{42} \gg$. Il n'est pas jusqu'à la publicité commerciale, le management et l'industrie du spectacle qui ne dédaignent d'utiliser des éléments de l'insurrection surréaliste (décoration de vitrines, techniques de vente, brainstorming, pop'art, etc.). Le message détourné de sa destination révolutionnaire sert finalement le philistinisme bourgeois le plus affairiste. La négativité et le dépassement spécifique de la création artistique n'agit pas sur les esprits au point d'informer de proche en proche la vie de tous. Aucun nouveau style de vie n'est vraiment induit par cette pratique. Quoi qu'il en ait, l'art dit pur, abstrait, formaliste est en fait piégé par un réseau de conditionnements qui travaillent pour la reproduction de l'ordre social.

Les notes éditoriales qui ouvrent le premier numéro de l'I.S. méditent sur cette «amère victoire du surréalisme»:

Dans le cadre d'un monde qui n'a pas été essentiellement transformé, le surréalisme a réussi. Cette réussite se retourne contre le surréalisme qui n'attendait rien que du renversement de l'ordre social dominant.

42. R. Vaneigem, Traité..., p. 186. 
La révolution n'étant pas faite, tout ce qui a constitué pour le surréalisme une marge de liberté s'est trouvé recouvert et utilisé par le monde répressif que les surréalistes avaient combattu.

L'emploi du magnétophone pour instruire des sujets endormis entreprend de réduire la réserve onirique de la vie à des fins utilitaires dérisoires ou répugnantes ${ }^{43}$.

À travers cette critique de l'impasse historique du surréalisme, c'est indirectement l'aventure lettriste elle-même qui est ainsi mise en question. Pourtant ce diagnostic d'inspiration marxiste ne cesse d'entretenir un certain quant-à-soi critique vis-à-vis de la théorie même de Marx (notamment à l'égard de l'art) ${ }^{44}$, autant que vis-à-vis des régimes, des partis et des syndicats qui s'en réclament. Si le mépris supérieur à l'égard des «crapules statliniennes» et du stalinisme par les communistes eux-mêmes est aujourd'hui de bon ton, il faut convenir qu'il n'en était rien à l'époque. Quand les situationnistes affirmaient alors «la nécessité, pour un mouvement révolutionnaire dans la culture, de reprendre à son compte, avec plus d'efficacité, la liberté d'esprit, la liberté concrète des moeurs, revendiquées par le surréalis$\mathrm{me}^{45}$, ils étaient en avance sur les gauchistes de Mai 68. Ils ressentaient déjà dans les sursauts de la révolte de la jeunesse contre l'ennui mortel de la vie quotidienne un état d'esprit analogue à celui des surréalistes. Mais, en même temps, ils observaient que la mutation des révoltes en révolution n'était pas mûre, «de sorte que la résignation est le fond sonore de ce négativisme spontané de la jeunesse américaine, scandinave ou japonaise ${ }^{46}{ }_{\gg}$. Le dégoût et la fureur des jeunes à travers le monde répercute sur une vaste échelle la sensibilité dadaïste et surréalis$\mathrm{te}^{47}$; ils sont vaguement prêts à transposer l'esprit ludique et

43. I.S., $1 / 3$.

44. Ils se déclarent certes marxistes, mais «bien autant que Marx disant «Je ne suis par marxiste» (I.S., 9/26).

45. I.S., 1/5.

46. $1 . S ., 1 / 4$.

47. La première exhale son dégoût: «Dada a été la matérialisation de son dégoût», déclarait Tzara en 1923 (in L'Arriviste Tzara va cultiver ses vices).

La seconde est révélée par un document interne communiqué par $R$. Queneau à M. Nadeau: "Les membres soussignés de la Révolution surréaliste réunis, le 2 avril 1925, dans le but de déterminer lequel des deux principes surréaliste ou révolutionnaire était le plus susceptible de diriger leur action, sans arriver à une entente sur le sujet, se sont mis d'accord sur les points suivants:

"1. Qu'avant toute préoccupation surréaliste ou révolutionnaire, ce qui domine dans leur esprit est un certain état de fureur;

"2. Ils pensent que c'est sur le chemin de cette fureur qu'ils sont le plus susceptibles 
créateur de l'artiste dans la vie, mais leur inconscience politique et leur marginalité, souvent incomprise, laissent leur virtualités révolutionnaires en plan. Cette masse critique demeure une colonne errante que les forces politiques radicales regroupées à l'intérieur de puissantes organisations n'ont pas su reconnaître et attirer. Si le matérialisme marxiste révèle l'impasse de l'art comme activité séparée exercée par une élite même turbulente et iconoclaste, le marxisme historique ne se montre guère accueillant aux aspirations libertaires de l'artiste.

La mésaventure de Breton adhérant au PCF est éloquente à cet égard. Surréalistes et communistes oeuvraient également dans la ligne d'horizon d'une «libération totale» de l'homme. Le premier Manifeste et La Révolution surréaliste, puis l'ouverture, en 1924, du Bureau de recherches surréalistes (15, rue de Grenelle), indiquent assez que l'engagement surréaliste prétend être par lui-même et de plain-pied révolutionnaire. Mais les communistes ne l'entendaient guère de la même oreille; ils réagirent comme les propriétaires menacés de la nouvelle divinité. En 1926, La révolution et les intellectuels de Naville pose nettement la question: "Que peuvent faire les surréalistes?» L'année suivante, Breton entre au Parti, qu'il quittera d'ailleurs bien vite. En 1930, sous l'insistance d'Aragon, nous en sommes au ASDLR (le Surréalisme au service de la révolution) . . . En réalité, ils furent, les uns comme les autres, des Révolutionnaires sans révolution, comme l'a raconté l'un d'eux, A. Thirion.

Les situationnistes, soucieux de rendre chacun poète de sa propre vie, ont bien vu la difficulté de concrétiser leur volonté révolutionnaire en dehors du parti communiste. L'attitude ambiguë.des surréalistes fut à leurs yeux une "erreur». La poésie ne saurait être un appendice surajouté de la révolution sociale sans trahir la plénitude de sa destination démiurgique. De plus, elle ne saurait flanquer d'une manière extérieure une révolution ellemême monopolisée par des professionnels de la politique, une

d'atteindre ce qu'on pourrait appeler l'illumination surréaliste ...;

«3. Ils discernent pour l'instant un seul point positif auquel ils pensent que tous les autres membres de la Révolution surréaliste devraient se rallier: à savoir que l'esprit est un principe essentiellement irréductible et qui ne peut trouver à se fixer ni dans la vie, ni au-delà.» (Antonin Artaud, J.-A. Boiffard, Michel Leiris, André Masson, Pierre Naville, Histoire du surréalisme, 1945, 1964, p. 69.)

Il n'est pas sans intérêt d'observer que, dans sa réponse à la lecture du manuscrit de Vaneigem, Gallimard relève «sous la litote du titre une grande fureur» (I.S., 10/84). 
spécialisation séparée, un nouveau pouvoir: «Un révolutionnaire spécialisé ne sait pas jouer ${ }^{48}$.» Leurs rapports doivent être infiniment plus organiques. À vrai dire, la poésie doit informer, au sens fort du terme, la praxis révolutionnaire elle-même. La révolution de la vie quotidienne constitue le vrai poème de l'avenir; la poésie se dépasse dans la révolution totale et la fête permanente: «L'oeuvre d'art à venir, c'est la construction d'une vie passionnante ${ }^{49}$." Dans cette interprétation, l'art et la révolution résolvent conjointement, l'un par l'autre, les contradictions de leur existence séparée. La dissolution de leur essence actuellement distincte dans une existence radicalement nouvelle entraînera le saut qualitatif de l'homme mutilé à «l'homme total». Seule la fusion de la créativité esthétique et de la créativité politique peut induire le millénarisme accordé aux possibilités de notre temps. La troupe légère du surréalisme intimidée et fascinée par les gros bataillons communistes les a trop servilement suivis. L'espérance fraîche mais désarmée des premiers a été abusée par l'espérance des seconds, déjà minée par la pratique du pouvoir et ses tentations empoisonnées. Aussi bien, Vaneigem la juge-t-il sévèrement: «L'histoire a été le cauchemar dont ne s'éveillèrent jamais les surréalistes, désarmés devant le parti communiste, pris de court par la guerre d'Espagne, grognant toujours mais suivant la gauche en chien fidèles ${ }^{50}$.» En radicalisant sa prise de conscience politique, radicalisme qui atteint dans sa critique le parti communiste, ce nouveau gauchisme inverse la démission historique des surréalistes: «Il ne s'agit pas de mettre la poésie au service de la révolution, mais bien de mettre la révolution au service de la poésie. C'est seulement ainsi que la révolution ne trahit pas son propre projet. Nous ne rééditerons pas l'erreur des surréalistes se plaçant à son service quand précisément il n'y en avait plus. Lié au souvenir d'une révolution partielle vite abattue, le surréalisme est vite devenu un réformisme du spectacle, une critique d'une certaine forme du spectacle, une critique d'une certaine forme du spectacle régnant, menée à l'intérieur de l'organisation dominante de ce spectacle ${ }^{51}$."

\footnotetext{
48. I.S., 8/57.

49. R. Vaneigem, op, cit., p. 209

50. Ibid., p. 185.

51. I.S., $8 / 31$.
} 
Comme l'a fait ressortir Lénine dans L'État et la révolution, la théorie marxiste veut et annonce le dépérissement final de l'État et plus radicalement du politique: "Les antagonismes de classes une fois disparus dans le cours du développement, toute la production étant concentrée dans les mains des individus associés, alors le pouvoir public perd son caractère politique ${ }^{52}$.»Privé de son assiette sociale, le pouvoir politique doit s'effondrer. Dans l'eschatologie de Marx, des producteurs associés, gérant euxmêmes leur activité, donnent congé aux chefs parasites. L'originalité de l'I.S. tient ici dans une visée révolutionnaire anti-politique menée au nom d'une poétisation intégrale de l'existence. Pouvoir et poésie sont incompatibles. Tout pouvoir séparé ruine la possibilité d'une communication sans entraves. En effet, «le pouvoir vit de recel. Il ne crée rien, il récupère. S'il créait le sens des mots, il n'y aurait pas de poésie, mais uniquement de l' "information" utile. On ne pourrait jamais s'opposer dans le langage, et tout refus lui serait extérieur, serait purement lettriste. Or, qu'est-ce que la poésie, sinon le moment révolutionnaire du langage, non séparable en tant que tel des moments révolutionnaires de l'histoire, et de l'histoire de la vie personnelle? (---) Retrouver la poésie peut se confondre avec réinventer la révolution, comme le prouvent à l'évidence certaines phases des révolutions mexicaine, cubaine ou congolaise. (...) Toute révolution a pris naissance dans la poésie, s'est faite d'abord par la force de la poésie. (. . .) Le moment de la poésie réelle, qui «a tout le temps devant elle», veut chaque fois réorienter selon ses fins l'ensemble du monde et tout le futur. Tant qu'il dure, ses revendications ne peuvent connaître de compromis. Il remet en jeu les dettes non réglées de l'histoire. Fourier et Pancho Villa, Lautréamont et les dinamiteros des Asturies - dont les successeurs inventent maintenant de nouvelles formes de grève - les marins de Cronstadt ou de Kiel, et tous ceux qui, dans le monde, avec et sans nous, se préparent à lutter pour la longue révolution, sont aussi bien les émissaires de la nouvelle poésie ${ }^{53}$.»

Cette synthèse intime de la poésie et de la révolution porte toute leur espérance, le principe du dépassement historique des révolutions ratées de notre temps, les révolutions marxiste et

52. K. Marx, Manifeste du parti communiste, Éditions sociales, 1962, p. 46.

53. L.S., 8/30-32. 
surréaliste. La Poésie-Révolution constitue à la fois le symbole de la finalité révolutionnaire et la médiation réelle du passage de la société de l'ennui à la fête de l'homme total. En effet, la poésie non comme genre littéraire mais comme dimension existentielle de l'homme se réalisera dans la société nouvelle née de la révolution: chacun y deviendra dans la joie le libre créateur de luimême. L'esprit de jeu et de spontanéité créatrice remplacera la compulsion névrotique au travail en vue de la survie: la poésie sera le sens de la vraie vie devenue réalité. À la triade maudite du spectacle, de la séparation et du sacrifice succédera la triade unitaire de la participation, de la communication et de la réalisation. «La prochaine forme de société ne sera pas fondée sur la production industrielle. Elle sera une société de l'art réalisé. (---) Nous sommes des artistes par cela seulement que nous ne sommes plus des artistes: nous voulons réaliser l'art ${ }^{54}$.» D'autre part, la poésie, communion de l'individu et de la collectivité dans la fête, n'est pas seulement l'autre de la passivité et de la réification générale, mais elle enveloppe également une négation dialectique de la tradition révolutionnaire moderne. Cromwell, Robespierre, Lénine, Trotzsky, Mao ont été eux aussi à leur manière, souvent plus terrible que celle de leurs ennemis, des puritains implacables et les instigateurs d'une nouvelle tyrannie. Or, il n'est pas question de se sacrifier pour la Cause révolutionnaire! «La révolution cesse dès l'instant où il faut se sacrifier pour elle. Se perdre et la fétichiser. Les moments révolutionnaires sont les fêtes où la vie individuelle célèbre son union avec la société régénérée. L'appel au sacrifice y sonne comme un glas. (--) Quand l'insurgé commence à croire qu'il lutte pour un bien supérieur, le principe autoritaire cesse de vaciller ${ }^{55}$.»

Sur ce point Marx est nommément pris à partie: "La fête, c'est l'art impopulaire du peuple. Être créatif, c'est faire sa fête avec toutes les choses, à travers une récréation continue. Pareils à Marx qui a déduit une révolution de la science, nous déduisons une révolution de la fête . . . Une révolution sans fête n'est pas une révolution. Il n'y a pas de liberté artistique sans le pouvoir de la fête. $.56^{56}$ Il n'est pas davantage question de substituer une domination à une autre domination, mais d'anéantir toute auto-

54. I.S., 7/17, 9/25; cf. aussi 1/8, 9/41-42.

55. R. Vaneigem, op. cit., p. 112-3; p. 251.

56. I.S., $7 / 39$ 
rité. Car «depuis les révolutions bourgeoises, aucune révolution n'a encore réussi: aucune n'a aboli les classes. (---) Jusqu’à présent la tyrannie n'a fait que changer de mains. (---) Dès que le meneur de jeu se mue en dirigeant, le principe hiérarchique sauve sa peau, la révolution s'assied pour présider au massacre des révolutionnaires $^{57}$." La nouvelle méthode révolutionnaire, si elle doit garder la dureté qu'il convient vis-à-vis des ennemis, doit éliminer toute pointe d'ascétisme et d'autoritarisme qui s'est régulièrement transmise des dirigeants révolutionnaires à la «nouvelle société»: «Le prolétariat brisera le mur des contraintes par le souffle de son plaisir et la violence spontanée de sa créativités8.» Sans doute en réaction contre l'ascétisme lié à l'eschatologisme des «lendemains qui chantent», les situationnistes entendent ne rien rabattre de leur «fureur de vivre». Désenchantée par les promesses non tenues, désabusée par le mensonge des modèles révolutionnaires, la génération du Paradise Now lui oppose un joyeux «présentisme». En dépit de leur dégoût du monde actuel, ils refusent de sacrifier à l'idole abstraite d'un Avenir lointain, fût-ce à la manière des militants au nom de la Révolution: «Leur temps de créativité, ils le passent à distribuer des tracts, à coller des affiches, à manifester, à prendre à partie le président de l'assemblée régionale. Ils militent. Il faut bien agir puisque les autres

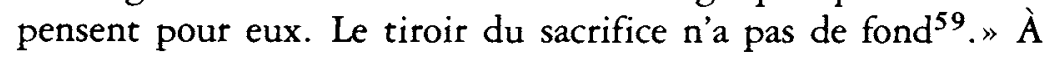
l'encontre de ce futurisme dévorant, ils veulent étreindre avec passion la chair frémissante du présent. Contre l'esthétique raffinée des surréalistes, contre le mépris «réaliste» des révolutionnaires professionnels devenus nouvelle classe politique, ils incarnent l'esthétique «sauvage» de la jouissance immédiate proclamée sur les murs de Paris en Mai 68 et dont plusieurs sont d'origine situationniste: "Jouissez ici et maintenant", "Vivez sans temps mort, jouissez sans entraves», "Ne travaillez jamais», "Sous les pavés la plage», "Je prends mes désirs pour des réalités, car je crois à la réalité de mes désirs", "Aimez-vous les uns sur les autres", etc. Indépendamment des critiques précises qu'ils peuvent décocher aux puritains de tous bords ${ }^{60}$, cette libération

57. I.S., 12/13; Vaneigem, op. cit., p. 59.

58. Ibid., p. 220 .

59. Ibid., p. 111 .

60. On sait qu'ils ne s'en privent pas, et souvent avec une ironie féroce. «Aussi la vertu du sacrifice est partout prônée. Aux prêtres rouges s'unissent les bureaucrates oecuméniques. Vodka et lacryma-christi! Entre les dents plus de couteau, la bave du Christ! Sacrifiez-vous dans la joie, mes frères! Pour la Cause, pour l'Ordre, pour la Révolution, pour le Parti, pour l'Union, pour le boeuf en daube!" (ibid., p. 110-111). 
totale du désir constitue déjà par elle-même une transgression révolutionnaire des interdits. Sade, Fourier et, d'une manière générale, les hérétiques des grands moments révolutionnaires, les infatigables dénonciateurs des fausses limites des révolutions refroidies prennent, ici, une valeur de symbole. Dans le panthéon situationniste, ils apparaissent comme les héros prophétiques du temps vengeur de la liberté totale: «La longue révolution se prépare à écrire dans les faits le geste dont les auteurs anonymes ou inconnus rejoindront pêle-mêle Sade, Fourier, Babeuf, Marx, Lacenaire, Stirner, Lautréamont, Léhautier, Vaillant, Henry, Villa, Zapata, Makhno, Les Fédérés, ceux de Hambourg, de Kiel, de Cronstadt, des Asturies, ceux qui n'ont pas fini de jouer avec nous, qui commençons à peine, le grand jeu sur la liberté ${ }^{61}$." Comment ceux qui rêvent d'entraîner les autres dans la société enfin régénérée peuvent-ils ne pas vivre déjà, dans la lutte ellemême, la liberté qu'ils prétendent apporter? Sans le goût de la célébration festive de l'actuel, l'activisme politique fait le lit d'une nouvelle illusion révolutionnaire et finalement expire dans la tristesse d'une autorité rajeunie. Sans la volonté de transformer le monde, l'espoir rimbaldien de changer la vie s'évapore en velléités anhistoriques.

On le voit, cette conception repose, au fond, sur une esthétisation du politique et une politisation radicale de l'esthétique ${ }^{62}$. Parti d'un milieu artistique, le groupe n'a cessé de se politiser toujours davantage. Pourtant cette évolution n'est pas parvenue jusqu'à la disparition du premier terme de l'arc dialectique: la politique semble envisagée comme une matière indéfiniment plastique, ductile aux intentions de l'esprit poétique; inversement, la poésie s'accomplit dans la révolution «faite». «La créativité est par essence révolutionnaire ${ }^{63}$.» La confusion systématique de l'art et de la révolution reflète sur le plan synchronique ce parcours.

Cet appétit de vivre et de jouir sans limites, s'il est allié à un tranquille septicisme moral et métaphysique, peut tourner le dos 61. Ibid., p. 62 .

62. Au niveau individuel, cette interprétation implique logiquement pour ceux qui y croient un nouveau style de vie et donc une nouvelle éthique: «Les groupes qui admettent l'échec non circonstanciel mais fondamental de l'ancienne politique, devront admettre qu'ils n'ont droit à l'existence comme avant-garde permanente que s'ils donnent eux-mêmes l'exemple d'un nouveau style de vie - d'une nouvelle passion.» (I.S., 7/16.)

63. Vaneigem, Traité..., p. 116. 
à l'Histoire. Nous sommes alors en face d'une forme de libertinage plus ou moins aristocratique. Mais s'il communie sans réserve au mythe moderne de la Révolution, nous découvrons alors les caractères typiques du millénarisme gauchiste que $\mathrm{J}$. Brun appelle «sexo-gauchisme ${ }^{64}$ » et dont le livre de Vaneigem constitue l'une des expressions les plus remarquables.

Tout d'abord le monde social se divise en deux parts selon un clivage manichéen rigoureux:

$$
\text { nous }=\text { bien; eux }=\text { mal. }
$$

À cette division sociologique se superpose une division selon un axe temporel:

$$
\begin{aligned}
& \text { maintenant }(t 1): \text { nous }=\text { rien; eux }=\text { tout } \\
& \text { bientôt }(t 2): \text { nous }=\text { tout; eux }=\text { rien. }
\end{aligned}
$$

L'irruption de la totalité signifie: fin de tous les dualismes, communion universelle, liberté totale, fête permanente, poésie réalisée, rachat de toutes les injustices, bonheur, etc. Cette dichotomie abrupte et cette anticipation passionnée de l'émancipation générale appellent une stratégie du passage de $t 1$ à $t 2$. Cependant, la souffrance intolérable de $t 1$ et la croyance blindée de $t 2$ tend à escamoter ce renversement subit d'un extrême à l'autre. L'urgence du passage énerve quelque peu le calcul des forces en jeu.

La réflexion stratégique ramène les lourdeurs et les complexités, les folies et les résistances de l'homme concret que l'utopisme sous-estime allégrement.

Par toute sa structure mythique, le millénarisme écarte d'emblée toutes les positions dialectiques et l'esprit de tolérance. Avec lucidité, Vaneigem reconnaît son génie manichéen et son potentiel anarcho-révolutionnaire. Bon gré mal gré, nul n'échappe alors à la violence inexpiable d'un combat final dans l'ici-bas. "Pourquoi, demande-t-il, saint Augustin combat-il les manichéens avec tant d'âpreté? C'est qu'il a mesuré le danger d'un mythe qui n'offre qu'une solution, la victoire du bon sur le mauvais. (--) Comme on comprend l'intérêt porté par la hiérarchie apostolique et romaine à la querelle du manichéisme et du

64. J. Brun, La nudité bumaine, Fayard, 1973. 
trinitarisme! Dans un affrontement sans merci entre Dieu et Satan, que fût-il resté de l'autorité ecclésiastique? Rien, les crises millénaristes l'ont prouvé ${ }^{65}$." Le christianisme, du moins dans sa veine pacifiste, celle du bon grain et de l'ivraie départagé dans l'au-delà par le Tiers suprême, "décompresse» les antagonismes historiques: "Le mythe chrétien désamorça l'âpre conflit manichéen en offrant au croyant la possibilité du salut individuel ${ }^{66}$." Dans la perspective radicale des situationnistes, la cohérence critique du groupe ne souffre pas de critique anti-critique: «Il faudra nous accepter ou nous rejeter en bloc. Nous ne détaillerons pas. ( . . .) Nous sommes les représentants de l'idée-force de la très grande majorité. Nos premiers principes doivent être hors de discussion ${ }^{67}$. Et comme dans toutes les sectes messianiques, le petit reste qui assume la détresse commune affirme en termes quasi explicites leur qualité de perfecti infaillibles: «Il me suffit d'être totalement vrai avec ceux de mon bord, avec les défenseurs de la vie authentique. (. . .) Nous ne nous sommes jamais assez considérés comme infaillibles. Cette prétention, nous l'avons laissée - par orgueil peut-être - à des formes figées, à des grandes rides: le pouvoir, Dieu, le pape, le chef, les autres. Et pourtant, chaque fois que nous nous référions à la Société, à Dieu,

à la Justice toute-puissante, c'est de notre pouvoir que nous parlions, mais si mal, il est vrai, si indirectement. Nous voici un étage au-dessus de la préhistoire. Une autre organisation humaine s'annonce, une organisation sociale, où la créativité individuelle va laisser libre cours à son énergie, imprimer au monde les contours rêvés par chacun et harmonisés par tous ${ }^{68}$.» Représentants du monde radieux qui vient, seuls ils échappent au conditionnement universel et détiennent la clé et la volonté de la libération totale. Le monde actuel dominé par les corrompus est placé sous le signe du Mal; le monde purifié du futur situationniste s'incarne déjà et d'abord dans les actuels membres de l'I.S.

La division du Traité, qui paraissait «artificielle» à l'éditeur Gallimard, exprime au contraire parfaitement l'antithèse insupportable du Mal et du Bien, de la division et de la totalité.

65. I.S., 8/46; Vaneigem, Traité.... p. 60.

66. Ibid, p. 61 .

67. I.S., 7/19-20.

68. Vaneigem, Traité..., p. $144,226$. 
Relevons la structure du livre de Vaneigem. La première partie, "la perspective du pouvoir», occupe 18 chapitres regroupés sous trois sous-titres principaux:

La participation impossible ou le pouvoir comme somme des contraintes;

La communication impossible ou le pouvoir comme médiation universelle;

La réalisation impossible ou le pouvoir comme somme de séductions.

«La survie et sa fausse contestation» boucle ce premier volet du diptyque.

La seconde partie, «Le renversement de perspective», s'étale sur sept chapitres qui constituent le vis-à-vis de la sinistre trinité du spectacle, de la séparation et du sacrifice. Et comme si cette dichotomie absolue pouvait échapper au lecteur myope, Vaneigem reprend inlassablement l'opposition du rien et du tout et recourt parfois à la majuscule pour lui donner tout son relief. "Nous n'avons pas choisi le renversement de perspective par je ne sais quel volontarisme, c'est lui qui nous a choisis. Engagés comme nous le sommes dans la phase historique du RIEN, le pas suivant ne peut être qu'un changement du TOUT. (. . .) Si nous ne renversons pas la perspective, c'est la perspective du pouvoir qui achèvera de nous tourner définitivement contre nous-mêmes. Le fascisme allemand est né dans le sang de Spartakus. Dans chaque renoncement quotidien, la réaction ne prépare rien d'autre que notre mort totale ${ }^{69}$.» Aussi celui qui oserait errer en quête d'un no man's land entre ces deux pôles ne peut être que rapidement broyé par cette alternative terroriste. Une affiche du Conseil pour le maintien des occupations (CMDO) dans la Sorbonne occupée en Mai 68 résume admirablement ce mouvement du zéro à l'infini:

Que peut

le mouvement

révolutionnaire

maintenant?

Tout

69. 1bid., p. 195. 


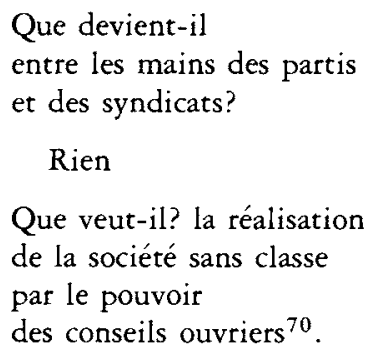

La dramatique millénariste veut l'imminence de la contiguïté des extrêmes. Parce que l'aliénation touche maintenant au fond de la misère, le salut ne peut être que prochain et total: «Ce sera maintenant ou jamais. (---) Jamais la corruption de l'humain n'a atteint un tel paroxysme. Jamais nous n'avons été si lointainement proches de l'homme total ${ }^{71}$." Nous sommes donc dans les derniers temps. Mais il n'est pas possible d'en douter: "les mauvais jours finiront ${ }^{72}$." Jusqu'ici, il est vrai, aucune révolution empirique n'a accompli la vérité idéale de la Révolution...: "Jamais, et pour cause, un affrontement absolu n'est arrivé à terme. La lutte finale n'a connu jusqu'à présent que de faux départs. Tout est à reprendre au début. La seule justification de l'histoire est de nous y aider ${ }^{73}$." Pourtant, il s'en est fallu de peu que Mai 68 réalise enfin cette espérance si longtemps nourrie. Dans le dernier numéro de l'I.S. (sept. 1969), Vaneigem, réaffirme sa croyance à la proximité historique de la vraie révolution prolétarienne: «L'imminence d'un bouleversement total, ressentie par tous, doit maintenant découvrir sa pratique: le passage à l'auto-gestion généralisée par l'instauration des conseils ouvrier$s^{74}$.» Par son essence particulière, le prolétariat échappe aux vulgaires objections des «réalistes»: «toutes les revendications sont réalisables dans l'immédiat, mais par lui seul ${ }^{75}$.»

Le dogme millénariste de Marx est repris dans une formulation légèrement nouvelle: «Les conseils ouvriers constituent un type nouveau d'organisation sociale par lequel le prolétariat met fin à la prolétarisation de l'ensemble des hommes ${ }^{76}$.» Sérieuse-




ment - «que la gravité des temps excuse la gravité du ton» ${ }^{77}$ Vaneigem soutient qu'un tel "objectif» est en vue; il est "permis d'espérer la fin de toutes les dualités, la règne de la totalité, la fin du pouvoir de l'homme sur l'homme. ( . . .) La chute du dernier bastion sacré sera la fin d'un monde ou la fin du monde ${ }^{78}$.»

Le rédacteur du long article sur Mai 68 , intitulé «le commencement d'une époque», va jusqu'à affirmer péremptoirement: «Si dans une seule grande usine entre le 16 et le 30 mai, une assemblée générale s'était constituée en Conseil détenant tous les pouvoirs de décision et d'exécution, chassant les bureaucrates, organisant son autodéfense et appelant les grévistes de toutes les entreprises à se mettre en liaison avec elle, ce dernier pas qualitatif franchi eût pu porter le mouvement tout de suite à la lutte finale dont il a tracé historiquement toutes les directives ${ }^{79}$.»

Certes, l'analyse de ces folles journées contient plusieurs éléments de réalisme stratégique, notamment l'insistance sur la nécessité d'étendre le mouvement des occupations, mais elle comporte aussi des illusions monumentales liées à la confusion voulue de la fête et de la révolution, du poétique et du politique: «Les révolutions prolétariennes seront des fêtes ou ne seront pas, car la vie qu'elles annoncent sera elle-même créée sous le signe de la fête. Le jeu est la rationalité ultime de cette fête, vivre sans temps mort et jouir sans entraves sont les seules règles qu'il pourra reconnaitre ${ }^{80}$." La perspective d'une guerre civile est envisagée comme «inévitable», et "l'invasion étrangère» comme «fatale», mais il rétorque aussitôt qu'il n'est pas sûr que «la contre-révolution armée» remporterait l'épreuve de force . . . On en conviendra aisément: dans ce mélange de réalisme et d'utopisme, celui-ci dépasse de loin celui-là. Dans un État moderne, «la prise de la parole», l'échange de pavés et de grenades lacrymogènes, l'occupation des universités et des entreprises ne suffisent pas à déclencher une vraie révolution qui implique nécessairement une prise effective du pouvoir. C'est le propre du révolution-

77. Vaneigem, Traité..., p. 9.

78. Ibid, p. 97-79.

79. I.S., $12 / 12$.

80. De la misère en milieu étudiant, considérée sous ses aspects économique, politique, psychologique, sexuel et notamment intellectuel, et de quelques moyens d'y remédier, par des membres de l'Internationale situationniste et des étudiants de Strasbourg, A.F.Q.E.S., 1966; Paris, 1967; brochure reproduite in Viénet, op. cit., p. 243. 
narisme actuel de parler d'autant plus de la Révolution qu'elle est moins «faisable». L'ivresse idéologique du bouleversement total inspire et commente tout à la fois des "gestes» symboliques, des "manifestations» politiques, des "scénarios pour la révolution", des chefs vedettes, une suite discontinue de happenings confusément assimilés à la "répétition générale» de la révolution accoucheuse du Millénium. Dans cette politique esthétisée, matériau conducteur d'un néo-millénarisme, l'efficacité spécifique du verbe et du geste est d'autant mieux reconnue qu'elle agit au niveau culturel d'une révolution du désir. La pratique systématique du «détournement» et de «la guérilla dans les mass-média» constitue l'expression conséquente de ce nouveau front révolutionnaire. Le «détournement» consiste à inverser les valorisations induites par la publicité, les photos-romans, les bandes dessinées (de préférence américaines). Le texte original des phylactères est effacé pour être rempli d'un nouveau texte porteur d'un sens critique. Le message des affiches publicitaires dans le métro, par exemple, est démystifié par l'adjonction de remarques parodiques. On peut même pousser le canular jusqu'à attribuer à une autorité des propos ridicules ou dégradants de nature à faire éclater le mensonge des déclarations officielles ${ }^{81}$. Ces opérations visent à démasquer les pseudo-valeurs régnantes, le néant de la vie quotidienne; elles ne peuvent prétendre à des bouleversements définitifs, mais préparent le terrain sur le plan des consciences.

En quête d'une authentique praxis révolutionnaire, l'action des situationnistes s'est maintenue sur un terrain plus idéologique que proprement politique. L'opposition institutionnalisée (partis et syndicats), viciée dans son principe, ne vise pas une mutation qualitative mais une nouvelle gestion du statu quo: elle

81. Après les "accords" de Grenelle, les situationnistes affichèrent sur les murs de Paris:

"À TOUS LES TRAVAILLEURS

Mesdames,

Mesdemoiselles,

Messieurs,

«Nous vous avons consenti, en accord avec l'ensemble de vos syridicats, plusieurs dizaines, d'heures de congés payés supplémentaires et de substantielles augmentations de salaires.» "À la veille des vacances d'été, nous vous suggérons donc de partir avec le Club Méditerranée et de ne plus vous préoccuper de "conseils ouvriers" et de "luttes de classes".

"Évitez même, s'il-vous-plaît, les occupations d'usines.

«Bien sincèrement,

Paris, le 7 juin 1968

(ln R. Viénet, op. cit., p. 191.)

Pour le C.N.P.F., le Président P. HUVELIN* 
sert déjà comme un mécanisme d'intégration des laissés pour compte de l'abondance.

La désaliénation ne peut venir que des éléments non intégrés, des parias en révolte. Les «blousons noirs» sont rangés dans cette catégorie, et en tant que tels les situationnistes se solidarisent avec cette jeune force sauvage. Dans leur numéro d'avril 1962 , il s'agit pour eux de «faire passer l'agressivité des blousons noirs sur le plan des idées». Par eux-mêmes, en effet, ils ne peuvent surmonter la contradiction dans laquelle ils se trouvent: «Ils méprisent le travail mais ils acceptent les marchandises. Ils voudraient avoir tout ce que la publicité leur montre, tout de suite et sans qu'ils puissent payer ${ }^{82}$.» Les Provos, influencés à l'origine par les situationnistes ${ }^{83}$, représentent la première forme du dépassement de l'expérience des «blousons noirs». Malheureusement, chez eux, «c'est le réformisme néo-artistique qui l'a emporté ${ }^{84}$ ». Les étudiants américains à l'Ouest, les hooligans à l'Est incarnent d'une manière encore abstraite le refus d'un monde pourri.

Le scandale de Strasbourg, à la rentrée de 1966, dont les situationnistes furent les instigateurs a constitué la première articulation révolutionnaire de la classe humiliée: "Nous pouvons affirmer, sans grand risque de nous tromper, que l'étudiant en France est, après le policier et le prêtre, l'être le plus universellement méprisé ${ }^{85}$." Après s'être fait élire à la tête du bureau de l'Association des étudiants, un groupe d'étudiants radicaux contacte des membres de l'I.S. De ces rencontres sortira, en novembre, la fameuse brochure De la misère en milieu étudiant, imprimée et distribuée aux frais de l'Association. Du même souffle, le bureau annonce que son intention est tout simplement d'obtenir, en assemblée générale, la dissolution de l'Association. $\mathrm{Si}$ on ajoute à cela le discours inaugural du cybernéticien Abraham Moles, accueilli par une pluie de tomates, on devine le climat de scandale qui flotta sur l'université.

Hostiles aux «Staliniens» mêlés au « 22 mars» lors de l'occupation administrative à Nanterre, les «enragés» quittèrent les

82. De la misère en miliet étudiant, déjà cité, p. 229.

83. Cf. E. Brau, op. cit, chap. V.

84. De la misère en milieu étudiant, déjà cité, p. 230.

85. Ils ne tardent pas à s'expliquer dans le $n^{\circ} 11$ de l'I.S.: «Nos buts et nos méthodes dans le scandale de Strasbourg". 
occupants avec fracas. On les retrouve aux côtés des situationnistes qui passent à un engagement plus concret avec le comité d'occupation de la Sorbonne. Mais là encore, leur intransigeance quant aux rapports théorie-praxis leur valut d'être rapidement supplantés par des organisations plus énergiques et surtout plus politiques dans leurs manoeuvres: Union nationale des étudiants de France (UNEF), Mouvement d'action universitaire (MAU), Jeunesse communiste révolutionnaire (JCR). Après leur départ, «jamais plus il ne fut question de faire réélire chaque jour par l'assemblée ses délégués révocables ${ }^{86}$ ».

Encore une fois la conviction millénariste de l'imminence d'une apocalypse révolutionnaire les porte à croire que la réalisation de «l'homme total» est désormais à portée de la main. Il suffit en somme de se prêter au jeu. "Le jeu devenant insurrectionnel provoquerait sans doute une réaction en chaîne, une onde de choc qualitative. (---) Il suffit d'une étincelle et d'une tactique adéquate. (--) Il suffit d'un coup d'épaule pour l'abattre, [le mur de l'aliénation], c'est au-delà seulement que tout commence. (...) Trois mille ans d'enténèbrement ne résisteront pas à dix jours de violence révolutionnaire ${ }^{87}$.»

La violence, surinvestie, apparaît alors comme le moyen passe-partout. Elle seule peut résoudre rapidement tous les problèmes sur lesquels butent depuis toujours les pesants calculs de la politique et télescoper le passage de $t 1$ à $t 3$ : «Rien ne résiste à la créativité armée. (...) Nous ne voulons pas être des justiciers, mais des maîtres sans esclaves, retrouvant, par-delà la destruction de l'esclavage, une nouvelle innocence, une grâce de vivre. Il s'agit de détruire l'ennemi, non de le juger. Dans les villages libérés par sa colonne, Durruti rassemblait les paysans, leur demandait de désigner les fascistes et les fusillait sur-le-champ. La prochaine révolution refera le même chemin. Sereinement. Nous savons qu'il n'y aura plus personne pour nous juger, que les juges seront à jamais absents, parce qu'on les aura mangés ${ }^{88}$."

L'ambiguïté du mouvement se concentre dans cette fascination de la violence. Tantôt elle figure comme médiation efficace du combat anarchiste, tantôt elle est goûtée pour elle-même

86. I.S., 12/23.

87. Vaneigem, Traité ..., p. 251, 226, 282.

88. Ibid., p. 272, 282. 
comme une source inédite de plaisir: "Les jouissances permises peuvent-elles se comparer aux jouissances qui réunissent à des attraits bien plus piquants ceux, inappréciables, de la rupture des freins sociaux et du renversement de toutes les lois ${ }^{89}$."

Tantôt elle est investie d'une attente eschatologique, tantôt elle est maniée comme méthode de provocation démystificatrice ou vécue comme fonction cathartique. Elle sacrifie simultanément à Prométhée et à Dionysos.

Les situationnistes affectionnent manifestement les formules frappées qui claquent comme des coups de fouet et sont immédiatement disponibles comme slogans. L'une d'elles semble cristalliser toutes leurs croyances, si l'on en juge par leur zèle à la diffuser aux quatre coins du globe: Amsterdam, Prague, Tokyo, Moscou, Pékin: «Tremblez, bureaucrates. Le pouvoir international des conseils de travailleurs va bientôt vous balayer. L'humanité ne sera heureuse que le jour où le dernier bureaucrate aura été pendu avec les tripes du dernier capitaliste ${ }^{90}$."

Le culte de la violence se déploie avec d'autant plus d'assurance qu'il se considère totalement légitimé par la cohérence d'une "théorie" révolutionnaire que les tentations du pouvoir n'ont pas encore édulcorée. Telle est la source de leur intransigeance critique et des vocations surdéterminées qu'ils conferent à la violence dite révolutionnaire. Convaincus que le cours de l'histoire, autant que l'affirmation totale du désir, entraînent la société moderne vers la société sans classes, ils critiquent sans ménagement toutes les sociétés existantes. Aucune ne trouve grâce à leurs yeux. Il va de soi que les régimes fascistes, les démocraties libérales dites bourgeoises, le Welfare State, la socialdémocratie, le socialisme «stalinistique», mais également l'autogestion yougoslave et la bureaucratie chinoise sont copieusement exécrés comme autant d'impostures. Toute positivité, par le fait même qu'elle actualise un possible, une forme sociale déterminée, brime la transcendance du désir, jamais satisfait de ses acquis, impatient de transgresser toute limite. La postulation utopique de l'avènement de la société sans classes constitue en fait le fondement non critique de leur critique universelle. Critiques

89. Viénet, op. cit., p. 76.

90. Viénet, op. cit., p. 275. 
aigus dans leurs diagnostics des régimes existants, ils ne doutent pas de l'inéluctabilité de ce devoir-être abstrait. Le poids de la bourgeoisie «l'entraîne irrésistiblement vers la dernière convulsion. ( . . .) La bourgeoisie assure un interrègne précaire et peu glorieux entre la hiérarchie sacrée des féodaux et l'ordre anarchique des futures sociétés sans classes ${ }^{91}$.» Que cette anticipation visionnaire de l'humanité future nie toute l'expérience des sociétés humaines n'ébranle aucunement la validité "théorique» de leur espérance. Qu'à côté et concurremment à cette philosophie de l'histoire, héritée du XIX ${ }^{\mathrm{e}}$ siècle, l'eschaton de l'histoire ait pu être envisagé comme l'avènement d'une race de seigneurs ne trouble pas davantage leur attente. Que la représentation des sociétés probables, idéales ou simplement possibles, puisse varier à l'infini et qu'aucune de celles que les hommes ont imaginées ne se réalise, voire que l'inimaginable se produise parfois, ne semble leur venir à l'esprit. Que des générations entières soient sacrifiées sur l'autel de tâches infinies au profit de quelques-uns, trop vertueux ou franchement cyniques, ne leur paraît pas un phénomène digne de leur réflexion.

La charge polémique à l'égard des «révolutionnaires»au pouvoir et l'exaltation de «moments» révolutionnaires ponctuels et sans suite - «une dizaine, au moins, de moments révolutionnaires d'une extrême importance historique ${ }^{92}$ - ne suscitent pas chez eux un examen critique des fins et des moyens de la révolution de leurs rêves. Déçus par l'embourgeoisement des masses et l'émergence d'une "nouvelle classe dirigeante" partout où des révolutions ont été faites au nom du prolétariat, ils invoquent une "troisième force", un "nouveau prolétariat» dont il est dit qu'il "tend à englober à peu près tout le monde», un "Front contre le travail forcé» dans lequel se trouvent réunis tous ceux qui résistent à la récupération par le pouvoir ${ }^{93}$ ».

Au lieu de virer à un scepticisme paralysant, leur lucidité à l'égard de l'empirie s'évade dans l'adoration des fins ultimes. Pourtant, ils rêvent comme le jeune Marx d'une critique radicale qui se dépasserait dans une action efficace: «Sans la critique des armes, les armes de la critique sont les armes du suicide. Quand

91. R. Vaneigem, op. cit., p. 127,74 .

92. I.S., 12/13.

93. I.S., $7 / 43 ; 8 / 42$. 
ils ne tombent pas dans le désespoir du terrorisme ou dans la misère de la contestation, bon nombre de prolétaires deviennent des voyeurs de la classe ouvrière, les spectateurs de leur propre efficacité différée ${ }^{94}$.» La violence de la critique aspire à s'achever dans un combat effectif, une lutte à finir avec «le vieux monde», une violence libératrice. Cependant, ils refusent du même souffle le recours à la violence des authentiques révolutionnaires, c'està-dire à la violence médiatisée par une organisation et une stratégie précises de la prise du pouvoir. Pour s'en tenir à notre siècle, Lénine et Mao ont compris et montré en actes la rigueur du combat révolutionnaire réel. Comme s'il fallait en faire la preuve à nouveau, la spontanéité en ce domaine ne mène à rien. Marcuse lui-même en convient maintenant et se retrouve pour une fois dans le camp des "réalistes»: "On ne pourra éternellement se passer d'organisation et de discipline. Comme l'a dit Engels, une révolution est la chose la plus autoritaire qui soit ${ }^{95}$." Or les situationnistes se rangent dans la lignée franchement millénariste de la grève générale ${ }^{96}$. Contre l'encadrement des syndicats, ils exaltent "la grève sauvage» et voient dans "la grève générale sauvage» de Mai 68 les prémices d'une révolution antiautoritaire. Il est vrai que cette «révolution» pure, non déformée, a été, elle aussi, différée. . ${ }^{97}$ L'action spontanée du prolétariat autonome, ils la voudraient immédiatement efficace; ils voudraient que les gestes désespérés des anarchistes relèvent en même temps d'une stratégie savante: «Il faut changer en espoir le désespoir des terroristes anarchistes; corriger dans le sens d'une stratégie moderne leur tactique de guerrier médiéval ${ }^{98}$. $\gg$ Mais là encore l'accent est mis sur des dispositions subjectives, l'audace et l'énergie de la volonté: "Que se rencontrent dix hommes résolus à la violence fulgurante plutôt qu'à la longue agonie de la survie, aussitôt finit le désespoir et commence la tactique ${ }^{99}$.» Ils imaginent des «individus agissant pour leur compte, se fédérant occasionnellement en commandos de sabotage (neutralisation des réseaux répressifs, occupation de la radio, etc.), intervenant où et

\footnotetext{
94. Vaneigem, Traité..., P. 290.

95. Dans une discussion avec Hans Magnus Enzensberger, Actuel $n^{\circ} 15$, décembre 1971 , reproduit in C'est demain la veille. p. 67, Seuil, 1973.

96. Voir Mühlmann, op. cit., p. 193, 320; H. Desroche, Sociologie de l'espérance, Calmann-Lévy, 1973 , p. 51 ss.

97. L.S., 7/15; Viénet, op. cit., chap. V

98. Vaneigem, Traité..., p. 206.

99. lbid., p. 26.
} 
quand l'opportunité leur offre des garanties d'efficacité tactique et stratégique, n'ayant d'autre souci que de jouir sans réserve et inséparablement d'attiser partout les étincelles de la guérilla ouvrière, le feu négatif et positif qui venu de la base du prolétariat est aussi la seule base de liquidation du prolétariat et de la société de classes ${ }^{100}$." Cette liaison insistante entre une éthique hédoniste et une politique anarchiste volontariste nous mène au coeur du syncrétisme idéologique des situationnistes. D'un côté, un appétit libertaire de jouissance totale et immédiate, de l'autre, une résolution abstraite d'efficacité concrète. Bien plus, cette bipolarité s'évanouit finalement dans l'identification pure et simple du premier au deuxième terme: «Le déchaînement du plaisir sans restriction est la voie la plus sûre vers la révolution de la vie quotidienne, vers la construction de l'homme total ${ }^{101}$." La lutte historique se confond avec la fantaisie fouriériste: «Quiconque ne découvre pas dans la révolution la passion pivotale qui permet toutes les autres n'a que les ombres du plaisir ${ }^{102}$." Cette disproportion entre la fin et l'indigence des moyens, entre une finalité eschatologique qui transcende la praxis révolutionnaire ellemême et une négation révolutionnariste ${ }^{103}$ de la stratégie politique, cette disporportion est typique de la mentalité millénariste. Le saut qualitatif du néant à la totalité n'est pas conçu comme l'oeuvre d'une action méthodique, mais comme une explosion apocalyptique: «Il s'agit de hâter la fin d'un monde, le désastre où les situationnistes reconnaîtront les leurs. (---) Nous n'organisons que le détonateur: l'explosion libre devra nous échapper à jamais, et échapper à quelque autre contrôle que ce soit ${ }^{104}$.» Le léninisme est l'anti-modèle. S'il faut chercher un maître, il faut plutôt le voir comme une sorte d'archange exterminateur exécutant sommairement les ennemis: «L'image-pilote serait la colonne Durutti passant de ville en village, liquidant les éléments bourgeois et laissant aux travailleurs le soin de s'organiser ${ }^{105}$.» La régénération totale de l'homme exige d'abord une épuration générale, «un point zéro où tout peut vraiment commencer ${ }^{106}$ ".

100. Ibid, p. 291.

101. Ibid., p. 125.

102. Ibid., p. 292.

103. Voir, là-dessus, le précieux article de J. Freund, “Le révolutionnarisme», Res Publica, $\mathrm{n}^{\circ} 3$, 1969.

104. I.S., $7 / 12,27 ; 8 / 28$. Souligné dans le texte.

105. I.S., $8 / 47$.

106. Vaneigem, Traité..., p. $80,123$. 
Les situationnistes ne prévoient pas de médiations institutionnelles de conciliation, sinon des volontés, du moins des conduites, pour la simple raison qu'une fois "le vieux monde" détruit, il ne devrait plus y avoir de conditions objectives à l'antagonisme des désirs. Bien que Vaneigem reconnaisse en passant que "ce qui produit le bien général est toujours terrible${ }^{107}$ ", toute sa mythologie politique présuppose une sorte d'harmonie préétablie et spontanée entre les monades individuelles, une attraction passionnée entre les atomes de l'unité universelle dès lors que sont levés les obstacles «historiques» à l'expansion naturelle du désir. Au vague du chemin concret de la libération s'ajoute le refus utopiste de décrire la destination, la réalisation de l'art et de la philosophie: «Les situationnistes n'arrivent donc pas face au monde avec un nouveau type de société: voici l'organisation idéale, à genoux! Ils montrent seulement en combattant pour eux-mêmes, et avec la plus haute conscience de ce combat, pourquoi les gens se battent vraiment, et pourquoi la conscience d'une telle bataille doit être acquise ${ }^{108}$." Mais en les entraînant de l'écriture et du scandale provocateur à l'occupation de la Sorbonne et des usines, Mai 68 a forcé l'I.S. à mettre sur pied un minimum d'organisation, le Conseil pour le maintien des occupations (CMDO). C'est ainsi que la pression des circonstances les amène rapidement à une différenciation interne de l'institution; le Conseil comprend trois commissions: la Commission de l'Imprimerie, la Commission des Liaisons, la Commission des Fournitures. Viénet convient que le CMDO souffrait d'un relent de "démocratie soviétique» et ne pouvait prétendre devenir une organisation conseilliste permanente. Cependant, l'expérience comporte des aspects positifs que n'aurait sans doute pas désavoués Rousseau: "Le C.M.D.O., pendant toute son existence, réussit une expérience de démocratie directe, garantie par une participation égale de tous au débats, aux décisions et à l'exécution. Il était essentiellement une assemblée générale ininterrompue, délibérant jour et nuit. Aucune fraction, aucune réunion particulière n'exsistèrent jamais à côté du débat commun ${ }^{109}$." Malgré le ton péremptoire de l'affirmation, il est permis de garder un certain scepticisme quant à la perfection et à la viabilité du

107. Ibid., p. 30 .

108. lbid., p. 287.

109. A. Viénet, op. cit., p. 168. 
Conseil, comme sa disparition rapide le suggère. Le petit "groupe en fusion», réchauffé par un "moment révolutionnaire», peut difficilement conserver sa cohésion au fil des jours et encore moins communiquer sa loi à la société globale. Bien plus, la crise peut aussi bien être l'occasion de divisions mortelles. Dans son Toast aux ouvriers révolutionnaires (octobre 1972), Vaneigem l'avoue pudiquement: «En ne disposant que de l'exclusion et de la rupture pour empêcher l'incessante reproduction du monde dominant dans le groupe, l'I.S. a montré ses limites et démontré son incapacité d'harmoniser les accords et les discords intersubjectifs110." Ceux par qui «l'homme total» devait arriver n'ont pas su s'accorder entre eux sur le sens et les voies concrètes de sa réalisation... La secte s'est elle-même divisée.

Après avoir montré quelque répugnance de principe contre le "perfectionnisme idéaliste» des constructions utopiques classiques, l'I.S. avait cependant formulé en août 1961 l'idée d'une "ville thérapeutique de jeu", une "micro-ville expérimentale, dans une île inhabitée proche des côtes méridionales de l'Italie ${ }^{111}$. En réalité, ils retournaient par ce biais dans l'ornière des lieux communs du genre. Comme l'a démontré $H$. Freyer, cette récurrence de la catégorie de l'insularité définit le phototropisme archétypique de l'imagination utopique. Après l'expérience vécue au CMDO, Vaneigem renoue avec cette pointe utopisante dans son Avis aux civilisés relativement à l'autogestion généralisée (septembre 1969) ${ }^{112}$. Le fantasme de l'île n'est pas expressément repris, mais l'idée d'un ilot social, «d'un petit groupe expérimental, quasi alchimique, où s'amorce la réalisation de l'homme total ${ }^{113}$ " n'a cessé de hanter l'imaginaire situationniste. Avec cet Avis, l'inflexion de l'utopisme à la détermination utopique se réclamant explicitement de Fourier est frappante; il marque un aboutissement inattendu après le refus de «l'organisation idéale» relevé dans le Traité, mais demeure conforme à l'affinité sociologique des millénarismes et des utopies. Le projet autogestionnaire en vient donc à l'esquisse utopique des «précisions» institutionnelles.

110. Vaneigem, Traité..., p. 289.

111. I.S., $6 / 40$.

112. I.S., 12/74-79.

113. I.S., 8/47. 
Au-delà de la destruction de l'État et de la «la plaisanterie du Soviet Suprême", tout est mis en oeuvre pour court-circuiter toute résurgence du monde ancien. Bien entendu, "l'assemblée générale est seule souveraine", mais cette proclamation de principe n'empêche pas de prévoir des conseils locaux, urbains, régionaux, internationaux. De plus, l'assemblée devrait élire et contrôler une section d'équipement, une section d'informatique, une section de coordination, une section d'autodéfense. Il semble évident que le consensus provenant de l'adhésion spontanée des volontaires puisse se maintenir sans contrainte par un recours massif aux techniques modernes de télécommunications. Les conflits ne pourraient venir, semble-t-il, que des retours offensifs des forces hostiles du monde extérieur; il reviendrait alors à la section d'autodéfense de protéger l'existence des «zones libérées». Au règne de la marchandise succéderait une économie d'un nouveau type comportant trois catégories: des secteurs prioritaires ( «l'équipement matériel nécessaire à la transformation permanente des conditions historiques»); des secteurs de reconversion; des secteurs parasitaires destinés à la suppression pure et simple: ceux qui y travaillent actuellement ne devraient pas rechigner à se reconvertir dans les secteurs prioritaires, 3 ou 4 heures par semaine. Quant à la taille des conseils locaux, elle devrait se limiter à une échelle restreinte: 8,000 à 10,000 personnes.

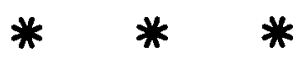

Consciente du cours irréversible et imprévisible de l'histoire et parfois des conséquences tragiques de nos choix, la sagesse grecque nous a enseigné la prudence et l'acceptation de la nécessité. Dans cette tradition, la démesure a été la faute par excellence. Entre les excès et les insuffisances, une éthique de la mesure s'est efforcé de faire cheminer l'homme au milieu de la route sans tracé des possibles. Étant donné la pauvreté des moyens, la logique de la situation a incliné à la poursuite de buts modestes.

C'est le judéo-christianisme qui a imposé le sens d'une histoire tendue vers sa fin comme vers son accomplissement. Avec le livre de Daniel, l'apocalyptique juive rompt avec l'espérance vétéro-testamentaire d'un bonheur intramondain pour le peuple élu et introduit la notion d'un salut pour tous au-delà de la mort, 
chacun selon ses oeuvres. En ramenant sur terre cette conception téléologique et unitaire de l'histoire, l'Aufklärung amène l'idée séculière d'un progrès humain lié au progrès des arts et des sciences. Avec Marx l'idée d'un salut universel n'est pas abandonnée, mais c'est la violence d'une classe déclarée universelle qui doit le réaliser dans l'en-deça de notre histoire. À travers Hess et Weitling, Marx renoue avec le fonds religieux de ses origines et réactive le thème prophétique de la prédestination sotériologique non d'un peuple, mais d'une classe sociale. Trop compromis avec les pesanteurs de l'histoire concrète, les marxistes pérennisent leur rôle de tuteurs du prolétariat et dénoncent les «gesticulations gauchistes.».

C'est dans ce contexte que les situationnistes en appellent à un «nouveau prolétariat» non encore assoupi par l'embourgeoisement et dont la misère psychique, l'ennui, le rend disponible pour l'aventure. Vaneigem diagnostique: «Une égale carence frappe les civilisations non industrielles, où l'on meurt encore de faim, et les civilisations automatisées, où l'on meurt déjà d'ennui ${ }^{114}$.» À partir de cette constatation, il est possible d'entrevoir un horizon bouché, l'homme du métro-boulot-dodo s'abondonnant à sa torpeur. Alors, "l'ennui est contre-révolutionnaire ${ }^{115}$ ». Mais on peut aussi espérer le sursaut de la révolte: «Nous ne voulons pas d'un monde où la garantie de ne pas mourir de faim s'échange contre le risque de mourir d'ennui ${ }^{116}$.» De proche en proche, le refus individuel peut déboucher sur une "agitation qualitative»: "De l'ennui peut naître à chaque instant l'irrésistible refus de l'uniformité. Les événements de Watts, de Stockholm et d'Amsterdam ont montré de quel prétexte infime pouvait jaillir le trouble salutaire. Quelle quantité de mensonges réitérés un seul geste de poésie révolutionnaire n'est-il pas capable d'anéantir?" Seule l'intransigeance de la foi qui soulève les montagnes peut provoquer la révolution, la «lutte finale». Malheureusement, "très tôt, les grandes idéologies lâchent la foi pour le nombre ${ }^{11^{17}}$. C'est cette pointe millénariste-utopique que les situationnistes retournent contre les «ancêtres», récupérés par les douceurs soporifiques de la société de consommation ou la griserie du pouvoir. L'eschatolo-

114. Vaneigem, Traité..., p. 82.

115. I.S., 7/16.

116. Vaneigem, op. cit., p. 8.

117. Ibid., p. 90-91. 
gie de l'bomme total ranime la flamme cachée du jeune Marx et, au-delà, l'utopisme du "génial Fourier ${ }^{118}$ ».

Mais en même temps qu' ils nourrissent la fièvre des sociétés chaudes de l'Occident moderne, ils aspirent au bonheur immédiat des sociétés froides. Impatients de faire l'histoire, d'accélérer son rythme dialectique, voire de l'achever, ils n'en éprouvent pas moins l'attrait d'un dionysisme mieux accordé au tempérament de la jeunesse. Le primitivisme obsède les sociétés surdéveloppées comme les réussites de la technique fascine «les damnés de la terre». Dieu mort, déçus et las du vacarme stérile de l'Histoire, le mythe de la vie intense fournit une alternative à la tentation du Rien. C'est sur ce second pôle que s'articule l'éthos esthético-érotique des situationnistes. Dans un monde dominé par le calcul et la rationalité instrumentale, la dépense excessive de la fête sauvage procure une inversion compensatrice des contraintes de la vie quotidienne. La libération ne peut être totale si elle n'entraîne dans son mouvement l'exaltation permanente du désir et des sens. La lutte historique se trahit elle-même si elle entretient en son sein la volonté de puissance des chefs, le sacrifice des militants et la servilité d'une masse apathique. Divorcé de la joie de vivre, le désir de la révolution installe en fait le double idéologiquement opposé de la société établie, une contre-société qui combat aussi bien les partisans authentiquement révolutionnaires de l'antisociété ... Seul l'esprit ludique vivifie à leurs yeux la pratique révolutionnaire et peut la mener à une communauté festive. La vie est assez généreuse pour ne pas s'épuiser dans l'utile, l'efficace, le rentable, le productif. Cet hédonisme libertaire est tellement fondamental qu'il finit parfois par absorber complètement le premier pôle de leur pensée. La stratégie disparaît alors au profit d'un activisme spontanéiste goûté pour lui-même comme un jeu particulièrement piquant. L'intensité du vécu subjectif l'emporte sur la recherche délibérée de résultats précis à l'intérieur d'un plan cohérent. Bien plus, c'est la joie communicative d'une vie passionnée qui créera la communauté nouvelle. Avec une stupéfiante naïveté, le Traité demande: "Comment va se créer la nouvelle collectivité révolutionnaire?» et répond aussitôt: «Par une explosion en chaîne, de subjectivité à subjectivité ${ }^{119}$." L'esthétique

118. Ibid,, p. 197.

119. Ibid., p. 170. 
elle-même, en tant que recherche formelle de la beauté, doit "dépérir» dans le pur jouir sensible . . . Pris à sa pointe extrême, l'art de notre temps ne se contente pas de dire la subjectivité dans des oeuvres «informelles", il dissout la notion même d'oeuvre d'art et fracasse "la Forme, la vieille entremetteuse du pouvoir120 ". La totale liberté du moi créateur doit être transposée de l'esthétique moderniste à la nouvelle politique révolutionnaire: «Renverser la perspective, c'est cesser de voir avec les yeux de la communauté, de l'idéologie, de la famille, des autres. C'est se saisir soi-même solidement, se choisir comme point de départ et comme centre. Tout fonder sur la subjectivité et suivre sa volonté subjective d'être tout ${ }^{121}$." C'est ce subjectivisme radical qu'Artaud a su, seul, maintenir contre ses compagnons trop pressés de se mettre au service d'une révolution qui n'en était déjà plus une: «Artaud a mille fois raison de s'en prendre à l'incapacité du mouvement surréaliste de fonder sa cohérence révolutionnaire sur ce qu'il contenait de plus riche, le primat de la subjectivité. Mais, sitôt consommée la rupture avec le surréalisme, on le voit s'égarer dans le délire solipsiste et dans la pensée magique. Réaliser la volonté subjective en transformant le monde, il n'en est plus question ${ }^{122}$.» Ainsi donc la révolution a encore une fois dérapé ... Résolue à faire l'bistoire jusqu'au bout, jusqu'à la révolution totale, sans rien sacrifier de la vie, l'I.S. ne cesse de critiquer la particularité des projets et des entreprises en recourant à des philosophies contradictoires qu'elle veut complémentaires - un fouriérisme converti à la violence révolutionnaire, un nietzschéisme délesté du principe hiérarchique, un marxisme "érotisé», libertaire, un suréalisme transformant la matière sociale, etc. Comme si la liberté totale, l'égalité absolue, le bonheur complet, la Justice, l'Amour devaient nécessairement se confondre dans la plénitude parfaite de l'bomme total. Comme si l'alchimie verbale garantissait la compossibilité de toutes les valeurs et l'illimitation de toute objectivation finie.

Grâce à cette confusion élective des catégories esthétiques et politiques, le gauchisme situationniste a lancé sur le supermarché spirituel un nouvel élément pour satisfaire le «besoin religieux"

120. Ibid., p. 100.

121. lbid., p. 174.

122. Ibid., p. 280. 
de la Totalité dans une société riche en moyens mais pauvre en finalités partagées. Il est compréhensible que l'élément critique de la société, la classe culturelle et spécialement "les littéraires», habiles à exprimer leurs aspirations et leurs frustrations, développent réactivement des espérances à la mesure de leur «misère.» C'est ainsi qu'Ellul perçoit dans l'engouement actuel pour l'Utopie «le negro spiritual des intellectuels de l'Occident moderne ${ }^{123}$ ». La fabulation révolutionnariste devient d'autant plus proliférante qu'une authentique révolution s'éloigne davantage de leurs possibilités. Comme l'avait déjà vu Tocqueville au siècle dernier, la majorité des régimes démocratiques se montre socialement hargneuse et revendicatrice mais peu disposée aux grands élans révolutionnaires. Les sociologues qui n'ont pas été éblouis par Mai 68 en conviennent aisément: le fantasme de la révolution qui hante l'ultra-gauche est une illusion ${ }^{124}$.

Au-delà de l'analyse sociologique de la conjoncture actuelle, l'illusion du millénium ressortit à une philosophie critique de la religion. On l'aura compris, au-delà de l'extraordinaire variété de ses figures, le millénarisme peut être défini dans la perspective de Kant comme une excentricité de la religion, une religion hors des limites de la raison, une déraison de l'espérance. De même que le pouvoir n'est pas de soi mauvais bien qu'il apparaisse souvent dans notre expérience sous l'aspect terrible de la tyrannie, de même l'espérance de la totalisation du bien rivé au coeur de l'homme, l'aspiration au Souverain Bien, fournit parfois le support légitime d'un excès de religion. Dans cette optique la religion ne saurait être assimilée à une simple sacralisation du devoir, elle embrasse dans sa visée raisonnable l'intégralité du bien et par conséquent non seulement la vertu, mais le bonheur. Le désir indéterminé du bonheur ne peut constituer le fondement de la moralité, car il n'est par lui-même qu'un idéal de l'imagination, et non une idée de la raison. La raison pratique a dû éliminer le bonheur de sa sphère propre pour atteindre une notion pure de la

123. J. Ellul, Les nouveaux possédés, Fayard, 1973, p. 150.

124. Pour se limiter aux analyses d'auteurs français mentionnons parmi les plus connus:

R. Aron, La révolution introuvable, Fayard, 1968;

G. Martinet, La conquête des pouvoirs, Seuil, 1968;

J. Ellul, Autopsie de la révolution et De la Révolution aux révoltes, Calmann-Lévy, 1969 et 1972.

J. Duverger, Janus, Fayard, 1972. 
morale. La philosophie de la religion le réintègre dans l'empire de la raison pour que l'objet de la volonté soit total. Ce que la raison pratique demande, écrit Ricoeur dans une étude remarquable, «c'est que le bonheur s'ajoute à la moralité; elle demande ainsi d'ajouter à l'objet de sa visée, pour qu'il soit entier, ce qu'elle a exclu de son principe, pour qu'il soit pur ${ }^{125}$ ". Ainsi, cette exigence de totalité ou d'accomplissement n'est pas immédiatement proscrite comme pathologie du désir; encore faut-il qu'elle demeure dans les limites de son statut d'idée. L'espérance du Souverain Bien est sensée, mais elle ne peut que se mouvoir dans l'horizon ultime et inaccessible de la volonté. De ce que l'horizon recule en même temps que le marcheur on ne doit pas conclure que l'idée de souverain bien n'est qu'une douce et vaine chimère, mais qu'elle apporte une orientation pleine de sens à l'action pourvu qu'on ne se mette pas en frais de la réaliser ici et maintenant. L'intention toujours ouverte d'achèvement et de réconciliation des contraires est saine et raisonnable; le mal surgit lorsqu'on prétend remplir dans l'expérience particulière, et par conséquent d'une manière prématurée, une synthèse qui n'est susceptible que d'approximations indéfinies. L'idée de souverain bien ouvre un espace illimité mais idéal qui ne saurait se refermer sur aucun projet empirique sans commettre une sorte de «fraude dans l'oeuvre de totalisation ${ }^{126}$ ». La liaison du bonheur et de la vertu n'est pas en notre pouvoir, elle est transcendante.

Avec une rigueur systématique exemplaire, Kant débusque l'insidieuse tentation totalitaire non seulement au plan de l'action, mais d'abord au plan de la connaissance. Tel est le sens de la critique de l'illusion transcendantale: nul discours ne peut se hisser jusqu'au savoir absolu. Le savoir total définit l'idée même du savant, mais elle est une tâche infinie. De la même manière, l'idée d'une réalisation totale des requêtes de la raison pratique excède les ressources d'un esprit fini et d'une liberté affectée par «le mal radical». On ne peut pas ne pas espérer au moins confusément la totalité, mais elle ne peut être qu'espérée; elle ne peut être ni connue ni effectuée. Quiconque prétend le contraire ne peut être qu'un imposteur et l'instigateur d'une nouvelle tyrannie. La

125. P. Ricoeur, «Approche philosophique du concept de liberté religieuse», in L'berméneutique de la liberté religieuse, Aubier, 1968, p. 227.

126. Ibid., p. 233. 
visée de la totalité bascule dans le totalitarisme dès lors qu'un pouvoir spirituel et/ou temporel s'avise de la réaliser dans les circonstances toujours particulières de notre histoire. La religion vire alors à l'exaltation ou à la folie religieuse qu' une longue suite de philosophes depuis Locke, Leibniz, Bayle, Spinoza, Shaftesbury, Addison, Voltaire, Diderot, Hume n'ont cessé de stigmatiser sous le nom d'enthousiasme, de fanatisme, d'intolérance et que Kant appelle la Scbwärmerei. Le prophète ivre de Dieu ou de la Fête-Révolution (peu importe le terme de la référence) ${ }^{\mathbf{1 2 7}}$, qui trouve un milieu favorable à sa prédication et réussit à communiquer sa certitude enfiévrée à un groupe, enclenche un mouvement millénariste. Or, quoi qu'il fasse, qu'il soit violent ou non violent dans ses méthodes, il n'arrivera jamais à créer un homme nouveau, un homme total. Plus souvent qu'autrement la violence tentera de forcer la distance qui le sépare du «règne des fins». Mais, du moment que le leader refuse la violence, il n'est pas dit que ses disciples soient disposés à s'en abstenir longtemps. L'exemple des massacres de 1947 en Inde nous force à nous interroger à ce sujet.

Il pourra peut-être fonder une nouvelle unité politique et/ou religieuse, mais sa carrière historique sera généralement éphémère sous la forme qu'il avait entrevue au départ. À l'effervescence de la fondation succède une phase de consolidation et d'organisation en vue de la durée. Or les vertus nécessaires pour la phase d'assaut ne sont pas nécessairement celles qui garantissent la régularité et la stabilité des institutions issues de l'esprit révolutionnaire; elles en sont bien plutôt la menace permanente. En effet, ou bien l'intransigeance de l'esprit révolutionnaire se conserve et renverse sans cesse toute positivité qui prétend exprimer la pureté de l'idée originelle, ou bien les politiques éliminent les doctrinaires (il n'est pas rare que l'élimination soit physique) et établissent un État ou une Église solide mais qui ne réalise que fort partiellement la révolution rêvée... Tel est le dilemme de toute révolution auquel nul n'a jamais échappé. C'est pourquoi les révolutions qui ont «réussi» suscitent périodiquement après elles de nouveaux prophètes qui se lèvent pour dénoncer «la

127. "De même que Dieu constituait le point de référence de la société unitaire passée, de même nous nous préparons à fournir à une société unitaire maintenant possible son point de référence central.» ( $R$. Vaneigem, I.S., 8/47.) 
révolution trahie» et auxquels le pouvoir répond parfois par un coup de piolet dans le crâne. . . Le doux rêve du millénium n'a jamais été réalisé et ne le sera jamais non parce qu'une mauvaise fortune poursuit leurs auteurs, mais parce que le règne des fins est, par sa nature même, un projet impossible, contradictoire. «L'espoir eschatologique d'une conciliation possible entre toutes les valeurs semble utopique, non seulement parce qu'une idée ne s'accomplit jamais dans sa pureté théorique, mais aussi parce que ces fins ne s'harmonisent pas conceptuellement ${ }^{128}$.» Le "polythéisme des valeurs" ajourne sine die le "règne des fins". Le but spécifique du politique ne consiste pas dans la régénération de l'humanité mais dans sa conservation, c'est-à-dire dans la paix. La politique concrète réalise ce but par la réalisation d'objectifs et la mise en oeuvres de moyens chaque fois limités. Il. n'existe pas de moyen passe-partout.

La catégorie du tout-tout-de-suite qui est au coeur du situationnisme est doublement anti-politique: par sa finalité transcendante, par son refus des médiations concrètes. Faut-il que l'appétit de croire soit profondément ancré en l'homme pour qu'il espère l'impossible plutôt que de sombrer dans le désespoir! Faut-il que le besoin d'espérer des temps meilleurs soit lié à la respiration humaine pour qu'en temps de crise la distinction entre la magie et la politique soit malaisée à établir!

Département de philosophie

Université de Montréal

128. J. Freund, "Justice et égalité", in Les études philosopbiques, avril-juin, 1973, p. 176. Du même auteur, voir aussi "Les politiques du salut", in Le point théologique, $\mathrm{n}^{\circ} 10$; "La détresse du politique", in Res Publica, n 3, 1972; "La violence des suralimentés", in Zeitschrift Für Politik, t. 19, cahier 3, Munich, 1972. Toute étude critique de l'impasse du prophétisme révolutionnaire ne peut ignorer aujourd'hui l'apport systématique de son grand livre, L'essence du politique, Sirey, 1965. 